\title{
LA DISCUSIÓN DEMOCRÁTICA SOBRE LA REVISIÓN JUDICIAL DE LAS LEYES DE DISEÑO INSTITUCIONAL Y MODELOS CONSTITUCIONALES
}

\author{
DEMOCRATIC OBJECTION AGAINST JUDICIAL REVIEW OF \\ LEGISLATION INSTITUTIONAL DESIGN ALTERNATIVES AND \\ CONSTITUTIONAL THEORIES
}

\begin{abstract}
Sergio Verdugo R.*
RESUMEN: Se revisa el argumento por el cual el control constitucional de la legislación aprobada por cuerpos electos popularmente, basado en la autoridad de jueces que se sitúan en una posición de preeminencia sobre los otros poderes del Estado, es contrario a la democracia. Tomando el argumento de Jeremy Waldron como referencia central, el autor discute algunas de las premisas sobre las cuales la objeción democrática se elabora. Sostiene que una separación entre la noción de supremacía constitucional y la idea de interpretación judicial final (y por tanto, suprema) permitirían construir un modelo que supere el problema democrático. El autor revisa algunas alternativas proporcionadas por diseños institucionales, y los sitúa dentro de la tradición jurídica europea continental para concluir que el debate acerca de la legitimidad democrática de la justicia constitucional es una discusión dinámica cuyo fundamento depende del movimiento de algunas variables específicas que el autor propone.

\section{Palabras clave: Justicia Constitucional, Democracia Constitucional, Revisión Judicial.}

ABSTRACT: This article reviews the argument through which judicial review of legislation approved by popularly elected bodies, based on the authority of judges who are in a position of preeminence on the other branches of government, is contrary to democracy. Taking Jeremy Waldron's argument as a central reference, the author discusses some of the assumptions on which the democratic objection of judicial review is elaborated. He argues that separating the notion of constitutional supremacy from the idea of judicial supremacy would allow building a model that overcomes the democratic problem. The author reviews some alternatives provided by institutional designs, and analyses the problem inside the civil law legal tradition. He concludes that the debate about the democratic legitimacy of judicial review is a dynamic discussion, and its foundation depends on the movement of some specific variables that the author proposes.
\end{abstract}

Key words: Constitutional Justice, Constitutional Democracy, Judicial Review.

\footnotetext{
Máster en Derecho, Universidad de California, Berkeley. Magíster en Derecho Público, P. Universidad Católica de Chile. Abogado, Licenciado en Ciencias Jurídicas, Universidad del Desarrollo. Profesor e investigador de la Universidad del Desarrollo y miembro del Centro de Justicia Constitucional de la Facultad de Derecho de dicha casa de estudios. Correo electrónico: sverdugor@udd.cl.

Todos los textos cuyos originales se encuentran en inglés, fueron traducidos por el propio autor.

Una versión parcial y preliminar de este trabajo fue presentada y discutida en una reunión del Departamento de Derecho Público de la Facultad de Derecho de la Universidad del Desarrollo, celebrada en agosto de 2011.

Agradezco a Sarah Song, Laurent Mayali, José Francisco García y Luis Alejandro Silva por las valiosas conversaciones realizadas. Agradezco también los comentarios de Raúl Campusano, Ignacio Covarrubias y Nicolás Enteiche. Además, destaco la colaboración del ayudante de la Dirección de Investigación de la Facultad de Derecho de la Universidad del Desarrollo, Nicolás Galli.
} 
"No siendo [...] más que una confección con signo negativo, la anulación de la legislación es, entonces, una función legislativa y la Corte que tenga el poder de anular la ley es, en consecuencia, un órgano de la rama legislativa".

Hans Kelsen ${ }^{1}$

"Es muy tarde para la vieja y cobarde historia acerca de jueces que no son responsables por construir argumentos como estos, [...] o de que es antidemocrático para ellos intentar, o que su trabajo es aplicar el Derecho y no especular acerca de moralidad. Esa vieja historia es filosofía también, pero es mala filosofía. Ella apela a conceptos-de Derecho y democracia-que no comienzan a entenderse".

Ronald Dworkin ${ }^{2}$

\section{INTRODUCCIÓN}

Se examinará el argumento democrático en contra de la existencia de un mecanismo de revisión judicial de las leyes basado en la supremacía constitucional. Para ello, se considerará la influencia de diferentes diseños institucionales, algunos derivados de tradiciones jurídicas y otros de sistemas políticos. Se demostrará que un cambio en la percepción de la supremacía constitucional basada en la autoridad (final) de los jueces, debiera modificar los alcances de la objeción democrática a la revisión judicial de las leyes. El objeto de este trabajo es defender la existencia de un modelo de supremacía constitucional construido sobre el diálogo entre las diferentes instituciones que participan dentro del sistema político, y argumentar que la existencia de lo que los norteamericanos denominan "departamentalismo" (departamentalism) hace que la objeción democrática a la justicia constitucional pierda fuerza, haciendo innecesaria su eliminación, mas no su revisión.

Utilizaré como referente del argumento democrático en contra de la justicia constitucional la tesis de Jeremy Waldron. La objeción de Waldron aspira a defender su idea de democracia mayoritaria, la que estima como incompatible a la existencia del control constitucional. Su crítica se dirige contra el poder de jueces no electos popularmente para invalidar leyes emanadas de instituciones elegidas democráticamente luego de un proceso que incluye elección, representación y deliberación ${ }^{3}$.

\footnotetext{
1 Kelsen (1928).

2 DwORKin (1996).

3 Probablemente, el trabajo más importante es Waldron (1999-A). Otro trabajo que ha causado impacto es Waldron (2006). No obstante que yo tomaré como referencia central estos dos trabajos citados (por ser los más directos en la materia), debe considerarse que Jeremy Waldron ha esbozado su crítica en otros artículos o libros, ya sea cuestionando el carácter legal de las normas constitucionales (WaLdron (2006-A)); defendiendo el rol de la legislación y de la regla de mayoría (WALDron (1999)); proponiendo un debate de autoridad en el contexto moral de desacuerdos sociales, mostrando que no existe una necesaria relación entre el tener un compromiso con los derechos fundamentales y la idea de establecer un listado constitucional de derechos (bill of rights) (WALDRON (1993)); o examinando la relación entre el realismo moral y la revisión judicial de las leyes (WALdron (1998)); entre otros trabajos.
} 
El objetivo de este trabajo es (i) identificar las formas en que su argumento puede ser refutado y (ii) examinar el valor de dos de ellas. La primera se basa en un supuesto de Waldron, por el cual se eligen como referentes del modelo constitucional que critica a Jon Elster y a Ronald Dworkin ${ }^{4}$. En este punto, argumentaré que Waldron critica una idea controvertida y limitada del constitucionalismo lo que, además de fortalecer su crítica, la hace menos importante.

La segunda refutación a Waldron radica en la problemática extensión del debate sobre la legitimidad de la justicia constitucional a sistemas diferentes al de EE.UU, y a tradiciones legales distintas a la anglosajona. No es adecuado "importar" esta discusión a otros sistemas constitucionales sin antes considerar aspectos relevantes de derecho comparado y modelos alternativos a aquellos a los que Waldron dirige su objeción.

El propósito de ese trabajo no es la defensa de la justicia constitucional como institución que toda democracia debería aceptar ${ }^{5}$. Solo persigo proponer un marco argumentativo para evaluar la procedencia de la objeción democrática.

Entre nosotros, la discusión democrática sobre la justicia constitucional ya está instalada ${ }^{6}$ y la función del Tribunal Constitucional ha sido cuestionada por diversos actores del sistema político ${ }^{7}$. A ello se suma la existencia de un grupo de fallos que han eliminado preceptos legales aprobados por cuerpos democráticos ${ }^{8}$. El interés por el tema que es objeto

4 Ver Elster (1984) y Dworkin (1996).

5 Ver algunos famosos trabajos que han justificado algún modelo de justicia constitucional: John Hart Ely se sustenta en la protección de elementos esenciales del sistema democrático, ELY (1980); Jon Elster justifica la justicia constitucional en la tesis del pre-commitment de la sociedad (más conocida como la metáfora de Ulises y las sirenas), Elster (1984); y Ronald Dworkin desarrolla una defensa que se basa en la protección de los derechos, Dworkin (1996). También es importante la posición de Bruce Ackerman, por la cual la Corte Suprema tiene un rol preservacionista, que permite mantener los principios establecidos popularmente frente al ataque de políticos en períodos de normalidad. Existen momentos constitucionales donde la ciudadanía transforma el sistema constitucional. La Corte debe proteger las decisiones adoptadas durante dichos momentos. Ver AcKERMAN (1993) y ACKERMAn (1998). En la tradición europea continental, ver entre otros a García de Enterría (2006 cuarta edición, primera edición de 1981).

6 Véase Atria (1993) y Atria (2000) y Zapata (2008).

7 Véase, por ejemplo, la crítica que el senador Escalona formuló cuando el Tribunal Constitucional rechazó la modificación parlamentaria al concepto de empresa que proponía el proyecto de ley de subcontratación, tildando a la magistratura constitucional de "poder fáctico". Diario El Mercurio, 29 de agosto de 2006. En un sentido similar, véase la objeción del senador Naranjo frente al fallo que declaró inconstitucional la resolución administrativa que permitía la distribución de la denominada "píldora del día después". El senador Naranjo tildó al Tribunal Constitucional de "suprapoder", y de "poder paralelo" que se atribuye atribuciones que "nadie se las ha otorgado". Diario El Mercurio, 12 de enero de 2007. Asimismo, y frente a la sentencia que declaró inconstitucional la actuación del Senado en el proyecto de ley del postnatal, véase la opinión del senador Rossi, para quien el Tribunal Constitucional actuó de manera política (no jurídica), cuestión compartida por el diputado Auth. Diario El Mercurio, 15 de julio de 2011.

8 El Tribunal Constitucional ha declarado la inconstitucionalidad de: (a) la delegación de facultades jurisdiccionales a un funcionario del Servicio de Impuestos Internos. Sentencia del Tribunal Constitucional Rol No 681, 26 de marzo del 2007; (b) la gratuidad del turno obligatorio que los abogados deben asumir en defensa de aquellas personas que no tienen la debida asesoría jurídica. Sentencia del Tribunal Constitucional Rol No 1254, 29 de julio del 2009; (c) la exigencia de pagar una multa para formular reclamos en materia sanitaria. Sentencia del Tribunal Constitucional Rol No 1345, 25 de mayo del 2009; y (d) la tabla de factores que permite elevar unilateralmente los precios de los planes de salud por parte de las Isapres. Sentencia del Tribunal Constitucional Rol no 1710, 6 de agosto del 2010. 
de este trabajo crece todavía más cuando se considera la existencia de decisiones judiciales que han impedido que prosperen determinados preceptos legales contenidos en proyectos de ley, interviniendo dentro del proceso de generación de leyes que lleva a cabo el Congreso?. También hay sentencias que, aunque no declaren la inconstitucionalidad con efectos generales de una norma legal, han producido tensiones con órganos electos democráticamente ${ }^{10}$.

Todos los ejemplos anteriores son una muestra de la tensión existente entre la justicia constitucional y la independencia con que autoridades ejercen las tareas para la cuales fueron electas democráticamente. ¿Tiene el argumento de Waldron cabida dentro del sistema y tradición chilena, como pretenden algunos autores ${ }^{11}$ ? Propondré considerar ciertos factores relevantes para contestar la pregunta anterior, revisando algunos diseños constitucionales alternativos en los sistemas políticos comparados y, también, la manera en que las diferencias entre tradiciones jurídicas pueden entregar elementos de análisis.

En primer lugar (I) explicaré brevemente el argumento de Waldron, observando que el mismo se encuentra dentro de una "escuela" más amplia. En este apartado, expondré algunos de los problemas generales que tiene el argumento, además de destacar la manera en que el mismo ha sido reducido por el propio autor.

En segundo lugar (II) clasificaré las maneras en que la objeción democrática puede ser respondida, distinguiendo diferentes tipos de debates y adelantando algunos de los puntos centrales de este trabajo.

En tercer lugar (III) desarrollaré con mayor profundidad la idea de constitucionalismo que Waldron ataca (la de Dworkin) y mostraré las razones por las cuales dicha idea no es la mejor. Argumentaré que, si dicha idea es correcta, entonces Waldron tiene razón. El problema es que Waldron no tiene razón justamente porque dicha idea es errada.

\footnotetext{
9 Ello ha ocurrido, por ejemplo, con: (a) la primitiva declaración de inconstitucionalidad del tratado internacional que establece la Corte Penal Internacional. Sentencia del Tribunal Constitucional Rol No 346, 8 de abril de 2002. Finalmente el constituyente derivado solucionó el vicio de constitucionalidad agregando una nueva disposición transitoria a la Constitución (ver ley de reforma constitucional $N^{\circ} 20.352$ del 30 de mayo del 2009), lo que produjo que el Tribunal Constitucional admitiera que el tratado entrara en vigencia. Véase sentencia del Tribunal Constitucional Rol No 1415, 24 de junio de 2009; (b) la exigencia de crear un registro de usuarios de cibercafés. Sentencia del Tribunal Constitucional Rol No 1894, 12 de julio de 2011; y (c) la actuación del Senado que modificó un proyecto de ley que extendía los beneficios de las mujeres en materia de postnatal. Sentencia del Tribunal Constitucional Rol No 2025, 20 de julio de 2011.

10 Así sucedió, por ejemplo, cuando el Tribunal Constitucional declaró (a) la inaplicabilidad del precepto legal que permite declarar el desafuero de parlamentarios por parte de las Cortes de Apelaciones. La jurisprudencia ha evolucionado. Véase Verdugo (2008). En otro ejemplo, se declaró (b) la inconstitucionalidad de la resolución ministerial que permitía la distribución de la píldora del día después. Sentencia del Tribunal Constitucional Rol No 740, 18 de abril del 2008. El Tribunal Constitucional falló en contra de lo que opinaba la mayoría de la población. En un ejemplo más, el Tribunal declaró (c) la inconstitucionalidad del plan del Ejecutivo de financiar el sistema de transporte público mediante préstamos (caso Transantiago). Sentencia del Tribunal Constitucional Rol No 1153, 30 de septiembre del 2008. En un último ejemplo, se declaró (d) la constitucionalidad de que el Presidente de la República nombre ministros de Estado que actualmente se desempeñan como parlamentarios. Sentencia del Tribunal Constitucional Rol No 1357, 9 de julio de 2009.

11 Véase, por ejemplo, la columna de opinión de Carlos Peña titulada Los Derechos en Serio (resulta curiosa la similitud con el título del libro de Dworkin) publicada en El Mercurio, 3 de septiembre de 2006.
} 
En cuarto lugar (IV) examinaré el alcance del debate democrático de la justicia constitucional de acuerdo a los arreglos institucionales en el que este se sitúa. Sostendré que dicho debate tiene menos espacio cuando (a) existen diseños que separan la idea de supremacía constitucional de la idea de supremacía judicial (los jueces no son los últimos ni los únicos intérpretes de la Constitución); (b) los tribunales con potestades de control constitucional están sujetos a diversas formas de accountability democrático ${ }^{12}$; y (c) la tradición jurídica debilita la función creativa de los jueces mediante técnicas como el literalismo y el originalismo en la interpretación de la norma jurídica.

Finalmente $(\mathrm{V})$ presentaré las conclusiones resumiendo las variables que deben considerarse para entender cuál es el espacio correcto que debe entregársele al debate democrático sobre la justicia constitucional.

\section{LA OBJECIÓN DEMOCRÁTICA, SUS SUPUESTOS Y PROBLEMAS PRELIMINARES}

La objeción a la legitimidad democrática de la revisión judicial de las leyes no fue inventada por Waldron, aunque la influencia de este último autor y la sofisticación de su argumento hacen que la crítica a la justicia constitucional no pueda ser examinada sin eludir su obra. El debate acerca de qué autoridad debe ser la encargada de velar por el cumplimiento de la Constitución se remonta (en los EE.UU.) a tiempos anteriores a la Constitución norteamericana ${ }^{13}$, y argumentos similares han sido elaborados por numerosos académicos y dirigentes políticos. Los actores políticos tienen incentivos ser críticos de la justicia constitucional (perturba su poder, hace gravoso su ejercicio, les quita autonomía, etc.); para aceptarla en términos parciales, en un escenario donde el efecto de la interpretación judicial de la Constitución es reducido (y no supremo) ${ }^{14}$; y, en ciertos casos, los políticos pueden servirse de la justicia constitucional cuando vean en ella alguna utilidad ${ }^{15}$.

12 La expresión inglesa accountability no tiene un sinónimo exacto en español, razón por la cual prefiero utilizar la voz en inglés. Ella significa una combinación entre rendición de cuentas y control. En el caso del accountability democrático, el control se puede realizar (aunque no exclusivamente) mediante la transparencia pública, la obligación de motivar o fundamentar las decisiones que se entregan, la existencia de mecanismos de remoción ejercidos por autoridades electas, entre otras.

13 Véase el panorama que se presenta en García (2003).

14 Hay muchos ejemplos. Es famoso el fundamento del veto del Presidente Andrew Jackson a una ley federal en el año 1832. El Presidente rechazó de manera explícita la interpretación de la Corte Suprema (en $M c C u l l o c h$ v. Maryland 17 U.S 316, 1819), exigiendo modificar la lectura constitucional y desconociendo la idea de supremacía judicial (aunque no la supremacía de la Constitución). Ver http://avalon.law.yale.edu/19th_century/ ajveto01.asp

15 En ciertos casos, los dirigentes políticos prefieren algunas materias controversiales sean resueltas por las cortes, de manera de eludir los costos (políticos) de la decisión y recibir los beneficios de ella. En general, ver Tushnet (2006). En Chile, es interesante el ejemplo de lo ocurrido en el caso Tohá, mediante el cual los parlamentarios se beneficiaron con una interpretación constitucional que les permitía ser nombrados ministros de Estado. Sentencia del Tribunal Constitucional Rol No 1357, 9 de julio de 2009. Ver, también, la polémica surgida en torno al procedimiento para desaforar a parlamentarios por delitos de acción penal privada, en VERDUGo (2008). 
Es relevante considerar que no toda preocupación por el menoscabo que sufre la democracia a raíz del ejercicio de la justicia constitucional, deriva ineludiblemente en la recomendación de eliminar la capacidad para revisar judicialmente las leyes. Así, por ejemplo, en 1893 James Thayer propuso reducir el ámbito de la revisión judicial sin suprimirla. Para Thayer, la inconstitucionalidad solo debiera ser procedente si el legislador ha incurrido en un claro error que no deje lugar a dudas ${ }^{16}$. Thayer prefería que los jueces constitucionales fueran moderados y ejercieran su potestad de control de la ley de manera prudente y deferente con los otros poderes estatales. La tesis de Thayer es, hasta el día de hoy, muy popular entre ciertos académicos y jueces (a quienes incluso se califica de thayerianos ${ }^{17}$ ) y, de manera más indirecta, en quienes han propuesto otras teorías análogas de autorrestricción judicial (self restraint), como ocurre con la teoría de la deferencia razonada, que Patricio Zapata promueve en Chile hace varios años ${ }^{18}$, y que ha sido invocada en algunas sentencias por el Tribunal Constitucional (citaré algunos ejemplos más adelante).

Uno de los autores más conocidos del pensamiento escéptico, Alexander Bickel, denunció lo que él denominó "dificultad contramayoritaria" (counter-majoritarian difficulty) de la justicia constitucional ${ }^{19}$, debido a que la revisión judicial de las leyes invalida decisiones adoptadas por órganos representativos de las mayorías políticas. Para Bickel, los jueces no electos que sirven inamovible y vitaliciamente, no le rinden cuentas al pueblo, como sí lo hacen los representantes electos mediante procesos democráticos periódicos, lo que altera la primacía de la regla de mayorías.

Hoy, la crítica democrática a la justicia constitucional es común entre los académicos, quienes presentan perspectivas diversas ${ }^{20}$. Un ejemplo es el del conocido politólogo, Robert Dahl, quien ha criticado la revisión judicial indicando que ella implica que los jueces estén capacitados para crear reglas sustentadas en sus convicciones personales ${ }^{21}$. Para Dahl, la justicia constitucional es sinónimo de legislación nueva creada judicialmente, lo

\footnotetext{
16 Thayer (1893).
}

17 Posner (2010) ha sostenido que las teorías thayerianas han muerto.

18 Zapata (1994) pp. 6-22; Zapata (2002) pp. 69-93 y Zapata (2008) pp. 225-289.

19 Bickel (1962 edición de 1986) pp. 16-22.

20 Ello ocurre con los casos de Larry Kramer y Mark Tushnet. Kramer defiende el rol del pueblo en la definición constitucional. Sostiene que los jueces no deben tener el monopolio en la interpretación de la Constitución y que el pueblo debiera tener la última palabra (no los jueces), lo que denomina constitucionalismo popular. En su trabajo, Kramer sostiene una concepción alternativa relativa al origen y a los límites de la revisión judicial en los EE.UU. Su visión aspira a revivir la idea de soberanía popular en un sentido práctico, y a la Carta Fundamental como parte de una realidad diaria. En el epílogo de su libro, Kramer propone una justicia constitucional sin supremacía judicial. Si bien los jueces tienen un rol valioso bajo el esquema de separación de poderes y de frenos y contrapesos (checks and balances), Kramer es partidario de sistemas judiciales que tengan más accountability, lo que ejemplifica con los tribunales constitucionales de Europa. La ausencia de la supremacía judicial haría remover obstáculos para la actuación política de otros poderes estatales y para la población, haciendo que las cortes sean más sensibles a ellos. Kramer (2004) pp. 249-253. Por su parte, Mark Tushnet sugiere "quitarle la Constitución a las cortes". Usando razones como las contenidas en la declaración de la independencia y en el preámbulo de la Constitución, Tushnet critica la supremacía judicial y promueve un "derecho constitucional populista”. Tushnet (1999).

21 Para Dahl, “[i]nevitablemente, en la interpretación de la constitución los jueces traen sus propias ideologías, prejuicios y preferencias”. DAHL (2002 edición del 2003) p. 55. 
que él rechaza firmemente 22 . Sin perjuicio de que este cientista político acepta la existencia del poder de las cortes federales con el objeto de "mantener el sistema federal"23, él también cree que la revisión judicial de las leyes es controversial, ya que la ley que se invalida ha sido creada por las ramas llamadas a legislar dentro de un gobierno democrático ${ }^{24}$.

Este trabajo solo se centrará en el argumento de Waldron, ya que este es probablemente el más crítico de la justicia constitucional, profundo y sofisticado, y ha producido un alto impacto en la literatura actual ${ }^{25}$. A diferencia de autores como Thayer y Kramer, Waldron es partidario de terminar derechamente con la revisión judicial de las leyes.

El propósito de Waldron es convencer a los ingleses de no adoptar el sistema norteamericano de revisión judicial ${ }^{26}$. Su crítica está dirigida principalmente a dicho sistema, aunque, como ya lo han hecho algunos autores citados en la introducción, es posible extender sus argumentos a otras realidades.

Waldron defiende una democracia orientada por la regla de mayoría, su aspecto procesal de ella y el derecho de participación política ${ }^{27}$. Si se supone un contexto de fuertes e inevitables de desacuerdos morales, el proceso mayoritario aparece como la mejor forma de tomar decisiones ${ }^{28}$. De esta manera, aquellas interrogantes morales que admiten respuestas alternativas (debido al desacuerdo) no debieran ser contestadas por cortes que no han sido electas y que se componen de jueces que también discrepan moralmente (como ocurre con el resto de la sociedad). Los jueces suelen estar divididos en las mismas materias en que la sociedad difiere (pena de muerte, derechos reproductivos y aborto, matrimonio homosexual, etc.), por lo que debiéramos respetar la dignidad democrática de la legislación ${ }^{29}$. De esta manera, Waldron busca proteger las leyes (la voluntad de la mayoría) ${ }^{30}$ de la revisión judicial $^{31}$. En este punto, el autor se ve en la necesidad de responder la objeción por la

22 DAHL (2002 edición del 2003) pp. 18-19.

23 DAHL (2002 edición del 2003) p. 54.

24 DAHL (2002 edición del 2003) p. 55.

25 A modo ilustrativo, la expresión "Law and Disagreement", más "Waldron", arroja 84.600 resultados electrónicos en la búsqueda de google.com; 1460 resultados en google académico; 169 resultados en el buscador académico de JStor; y 544 resultados en el buscador legal de HeinOnline.

26 Véase Waldron (1999-A) p. 16. Esta batalla no es nueva para Waldron, quien ya había planteado lo mismo en Waldron (1993) pp. 18-19 y en Waldron (1999) p. 4.

27 Ver capítulo 11 de WaLdron (1999-A).

28 Waldron (1999-A) p. 243. Cabe hacer presente que el problema del contexto moral de los desacuerdos, y la idea de establecer un debate de autoridad (donde se discuta quién resuelve dichos desacuerdos) ya había sido planteada por Waldron anteriormente. Véase WALDRON (1993).

29 Ver también WaLdron (1999).

30 Pese a ello, Waldron menciona de manera frecuente la "voluntad del pueblo" (the people's will) WALDRON (1999-A) p. 244. ¿Está el autor aludiendo a la democracia directa? Si la respuesta es positiva, entonces es fácil observar una contradicción con el sentido práctico que Waldron propone al situarse en el debate sobre la revisión judicial norteamericana e inglesa. Ello se debe a que ambos sistemas (incluso el inglés, al que Waldron tanto parece admirar) corresponden a democracias representativas. En este trabajo, asumiré que el autor alude a los modelos existentes, basados en las mayorías parlamentarias (y no necesariamente en las mayorías populares). Cabe hacer presente, no obstante, que mi supuesto se deriva de una razón lógica que Waldron no aclara de manera explícita.

31 "Hay algo que se pierde, desde el punto de vista democrático, cuando un individuo o institución no electo y que no rinde cuentas decide obligatoriamente aquello que la democracia requiere. Si hace la decisión correcta, 
cual la justicia constitucional es una manera de limitar una eventual tiranía de las mayorías (protegiendo a las minorías) $^{32}$.

Es importante hacer presente que constitucionalismo que Waldron critica se suele justificar teóricamente con una metáfora desarrollada por Jon Elster (sobre Ulises y las sirenas) ${ }^{33}$, a la que se agrega la visión práctica de los jueces que desarrolló Ronald Dworkin, en cuanto a la idea de la "lectura moral de la constitución" (moral reading of the constitution $)^{34}$. La versión del control constitucional refutado por Waldron se sustenta en estos dos pilares. La teoría de la lectura moral ha sido explicada dentro del contexto de la tradición jurídica anglosajona, que (para el propio Dworkin) intenta disciplinar y restringir el poder de las cortes mediante la exigencia del stare decisis (siguiendo el precedente vinculante), lo que se suele explicar con la tesis de la "novela encadenada" (chain novel theory) ${ }^{35}$.

El modelo que Waldron critica tiene las siguientes características: existencia de un listado de derechos; protección constitucional de las decisiones judiciales ${ }^{36}$; jueces no electos, y un debate pacífico con respeto mutuo ${ }^{37}$. Este último supuesto es empírico y sugiere muchas preguntas que nos permitirían reducir la aplicación de su argumento de manera notoria.

Waldron no solo está preocupado de un modelo específico de control constitucional, sino que también está preocupado del contexto sociomoral en que el mismo opera: desacuerdos en materia de derechos que se manifiestan en la sociedad y, también, entre los jue-

entonces - de seguro- habrá algo democrático que confrontar en contra de la pérdida; pero no es lo mismo a que no haya pérdida alguna en primer lugar. Por otro lado, si una institución electa y que rinde cuentas decide erradamente qué cosa requiere la democracia, entonces aunque exista una pérdida democrática en la substancia de la decisión, no es tonto para los ciudadanos sentirse cómodos con la creencia de que al menos cometieron su propio error acerca de la democracia (...)”. WALDRON (1999-A) pp. 293-294.

32 Waldron refuta esta objeción indicando que (1) la buena fe es el principio rector de la actividad de las personas (WALdRon (1999-A) p. 13); (2) cualquier proceso político puede conducir a una tiranía (WALDRON (1999-A) p. 258) y (3) existen diversas formas de tiranía (WALdron (1999-A) p. 299). Por su parte, Dworkin rechaza el argumento de la eventual arbitrariedad judicial señalando que cualquier autoridad puede volverse tiránica (Dworkin (1996) p. 11). Así planteadas las cosas, el debate Waldron-Dworkin se vuelve tautológico o circular (todos, jueces o parlamentarios) pueden ser tiránicos. Tal vez sea mejor plantear de nuevo la pregunta sobre la tiranía: ¿cuál es la autoridad (juez o mayoría parlamentaria) más proclive a ser tiránica? Esta pregunta ya fue planteada por A. Hamilton en el Federalista $N^{\circ} 78$ (ver Cooke, 1961). A mi modo de ver, si todos tienen capacidad (y probabilidad) de ser tiránicos, entonces todos debieran controlarse recíprocamente, y nadie debiera tener la última palabra. Ni los jueces, ni las mayorías parlamentarias, ni el Jefe de Estado. Esto nos obligaría a alterar el vínculo entre supremacía constitucional y supremacía judicial.

33 Ver, especialmente, Elster (1984).

34 Waldron (1999-A) p. 302. Waldron ve a la teoría de Dworkin como referente práctico del constitucionalismo aplicado por los jueces, y toma para ello, de manera especial, el libro Freedom's Law. Dworkin (1996). Por otra parte, debe hacerse presente que la justificación de Elster y la teoría de Dworkin tienden a contradecirse. Véase WALdron (1999-A) p. 265

35 Para Ronald Dworkin, la acumulación de capítulos de la "novela encadenada” persigue entregar disciplina y certeza al ordenamiento jurídico. Con ello, se restringe el ámbito discrecional de jueces-autores de novelas, a los que se les exige examinar toda la historia pasada (jurisprudencia anterior) para buscar la mejor decisión posible en el caso particular que deben resolver. Véase Dworkin (1986) pp. 228-244.

36 Waldron (1999-A) p. 221.

37 Waldron (1999-A) pp. 280-281. 
$\operatorname{ces}^{38}$. Sostiene que si existe desacuerdo, el control judicial no debería reemplazar la decisión pública de la mayoría ${ }^{39}$. Bajo su modelo (el que critica), aunque no lo diga expresamente, y para que su crítica funcione, es necesario que los jueces tengan la última palabra en la solución de los problemas sociales y morales de la sociedad (supremacía judicial ${ }^{40}$. La validez de este hecho dependerá de la capacidad y factibilidad de que nadie pueda revertir las decisiones judiciales, especialmente las de la Corte Suprema (en EE.UU., el símil en Chile sería el Tribunal Constitucional).

Vivimos en un contexto de fuertes desacuerdos morales y, no obstante lo anterior, los casos que se presentan requieren de una respuesta concreta (aun cuando estas puedan no ser ampliamente compartidas). Waldron denomina a este supuesto como "circunstancia de la política" ${ }^{41}$. Debido a esta "circunstancia", existe la necesidad de crear una regla, la que debería ser elaborada por el proceso político mayoritario. De esta manera, Waldron argumenta que la "circunstancia de la política" permite defender como razonable cualquier decisión que se adopte ${ }^{42}$.

El párrafo anterior representa un supuesto lógico y necesario para la teoría de Waldron, ya que permite vincular su ataque contra la revisión judicial con la idea de supremacía judicial. Es posible observar tres problemas en esta lógica.

El primero consiste en que es posible concebir un modelo de revisión judicial basado con el principio de supremacía constitucional, sin la noción de supremacía judicial ${ }^{43}$, por lo que resulta problemático suponer que lo contrario es una consecuencia ineludible.

Un segundo problema reside en que en la gran mayoría de los casos en que existen fuertes dilemas morales, la mayoría parlamentaria no entrega una regla clara de solución. El Congreso (a diferencia de los jueces) actúa de manera espontánea y no se rige por el principio de inexcusabilidad. Ello se explica por diversas razones: puede no existir voluntad política para entregar dicha regla de solución; se delega la solución del problema a otras instituciones (un comité de bioética, por ejemplo), o a las cortes jueces ${ }^{44}$; las normas que se entregan son producto de acuerdos negociados por grupos políticos que difieren en materias fundamentales; o simplemente el problema no ha tenido la suficiente relevancia pública como para interesar a los actores legislativos relevantes.

38 WALDRON (1999-A) p. 231, p. 267, p. 306.

39 WaLdron (1999-A) p. 295.

40 Él también rechaza el argumento acerca de la calidad del debate, que han hecho algunos defensores de la revisión judicial de las leyes. Mediante este argumento, el debate público se enriquece gracias a la fundamentación que la sentencia constitucional incorpora al sistema político. Waldron responde con un punto empírico WaLdron (1999-A) pp. 290-291. Además, Waldron rechaza el argumento hecho por Han Kelsen (aunque no cita a Kelsen), por el cual el legislador no puede ser juez de su propio caso, lo que se produce necesariamente cuando el control constitucional judicial es eliminado. Waldron contesta diciendo que los extraños (outsiders) al proceso político democrático no son bienvenidos en la elaboración de las reglas del sistema. Véase WaLdron (1999-A) p. 297. También, véase a KeLsen (1928 edición traducida en 2008).

41 Waldron (1999-A) p. 106.

42 Waldron (1999-A) p. 116.

43 Kramer (2004) pp. 249-253.

44 Véase Tushnet (2006) pp. 117-138. 
Debido a lo anterior, la regla de mayoría no siempre es un mecanismo útil para responder a la "circunstancia de la política". Si la mayoría parlamentaria no resuelve las preguntas morales (por ejemplo, al no pronunciarse sobre las diversas formas de eutanasia), es natural que ellas sean formuladas a los jueces competentes. En este punto hay un problema sin salida. Por un lado, si las cortes no entregan una respuesta concreta para los casos que se les presentan, el Estado de Derecho tendrá una seria falencia y, por otro, si los tribunales responden la pregunta moral (que no ha sido resuelta anteriormente por el proceso político), estarán legislando. El argumento de Waldron se inclina por privilegiar el rol de la mayoría parlamentaria, pero dicha solución no resuelve el problema de la inevitabilidad de los casos morales. Por eso, y mientras la respuesta política no se produce, es razonable entregarle una capacidad de respuesta a los jueces ${ }^{45}$.

El tercer problema del argumento de Waldron es que asume que es necesario que alguien deba tener la última palabra en la solución del problema moral (él se inclina por la mayoría parlamentaria y no por las cortes). Waldron no ha dado razones para justificar esta supuesta. No obstante, una necesidad como esa no parece evidente ni deseable en un sistema democrático. ¿No sería mejor que el sistema democrático cuente con procesos evolutivos, inclusivos y revisables en materias morales? Ello parece, a mi modo de ver, más coherente con un modelo de frenos y contrapesos y con un sistema constitucional de libertades. Volveré sobre este punto más adelante.

Estas tres debilidades descritas se distinguirán del resto de las respuestas posibles que clasificaré en el siguiente apartado, ya que ellas muchas veces se superponen a otros contraargumentos.

Además de estos problemas, hay que considerar que el ámbito de aplicación del argumento de Waldron ha sido reducido por el propio autor gracias a un trabajo posterior ${ }^{46}$. Mediante dicho trabajo, Waldron elabora cuatro supuestos sin los cuales habría más espacio para aceptar alguna forma de revisión judicial de las leyes. Dichos supuestos son: (1) la existencia de instituciones democráticas saludables que funcionen razonablemente bien ${ }^{47}$; (2) jueces independientes que trabajen razonablemente, proporcionando respuestas jurídicas a demandas individuales y aplicando el Derecho (rule of law) ${ }^{48}$; (3) la existencia de un fuerte compromiso con los derechos individuales y con la protección de las minorías ${ }^{49}$; y (4) la existencia de desacuerdos generales en la sociedad respecto de materias importantes ${ }^{50}$.

Como se verá más adelante, estos supuestos alteran la manera en que el debate puede situarse en Chile, ya que todos ellos admiten ciertos matices en nuestra realidad. Hay uno de ellos, no obstante, que debe ser contestado de una manera más general. Me refiero al tercero (3), por el cual debe existir un compromiso de las mayorías para proteger a las

\footnotetext{
45 En nuestra tradición civilista la solución al problema se encuentra en el método de la integración del Derecho que nuestro Código Civil acoge. A nivel constitucional encontramos una “omisión” legislativa. Véase mi trabajo Verdugo (2009).

46 WALDRON (2006).

47 WaLdron (2006) pp. 1361-1362.

48 WALdRon (2006) pp. 1363-1364.

49 WALdron (2006) pp. 1364-1366.

50 Waldron (2006) pp. 1366-1369.
} 
minorías. Waldron ha restado importancia al argumento de la tiranía de las mayorías en su trabajo anterior (como ya se explicó) pero no ha explicado satisfactoriamente de qué manera las mayorías podrían ser respetuosas de manera espontánea y sin requerir de un arreglo institucional que las obligue a ello, como ocurre con la justicia constitucional (otro ejemplo podría ser la exigencia de supermayorías parlamentarias para modificar ciertos cuerpos normativos de importancia ${ }^{51}$ ). Si se considera que la actividad de los dirigentes políticos se conduce motivada de manera racional en torno al incremento del poder (y la maximización de votos, en su caso), entonces es lógico suponer que existe un fuerte estímulo para que ellos alteren las reglas del sistema en su beneficio ${ }^{52}$. Así, por ejemplo, no sería extraño observar que modificaciones al régimen electoral o a las normas constitucionales que regulan el reemplazo de parlamentarios pudieran ceder en beneficio de amplias mayorías en el Congreso. Pese a lo anterior, el supuesto de Waldron descansa en la controvertible (y tal vez ingenua) idea de que las mayorías serán respetuosas de los derechos de las minorías. Este puede ser fácilmente refutado por simples y aceptados modelos de comportamiento político que el autor rechaza explícitamente ${ }^{53}$. Estos modelos, sin embargo, han servido como fundamento para el establecimiento de tribunales constitucionales en Europa continental, cuestión que Waldron no considera ${ }^{54}$, quien tampoco entrega evidencia empírica que sea capaz de demostrar la idea de que las mayorías parlamentarias respetan, en general, los derechos de las minorías.

\section{FORMAS DE RESPUESTA A LA OBJECIÓN DEMOCRÁTICA A LA JUSTICIA CONSTITUCIONAL}

A lo menos, hay tres maneras diferentes de responder la objeción de Waldron: (1) la respuesta empírica; (2) la contrarrespuesta democrática; y (3) la respuesta legalista.

Para (1) la respuesta empírica, los supuestos en que la objeción de Waldron se sustenta, son errados o, a lo menos, inexactos ${ }^{55}$. Uno de esos supuestos problemáticos, es la excesiva confianza de Waldron en favor de las mayorías parlamentarias. Hay dos maneras de controvertir esa confianza en las mayorías: aceptando un entendimiento distinto acerca de cómo se comportan las facciones políticas y bajo qué incentivos lo hacen ${ }^{56}$, o eviden-

\footnotetext{
51 Véase mi trabajo Verdugo (2009-A).

52 Ver, por ejemplo, el modelo económico de comportamiento político promovido en la literatura académica chilena por José Francisco García. García (2008).

53 Ver Waldron (1999-A) pp. 304-305, quien rechaza los modelos de comportamiento basados en el interés propio (self-interest models). Véase también a WALDRON (1999-A) p. 13, siendo optimista acerca del comportamiento del pueblo, el que actúa de buena fe (p. 13).

54 Así, por ejemplo, Dominique Rousseau ha dicho que los representantes no siguen necesariamente la voluntad de los representados, lo que produce una disociación y conduce a que los representantes tengan "intereses propios (...), encerrándose progresivamente en el juego de su competencia interna para preservar su posición (...). En definitiva, esta distinción entre gobernantes y gobernados, que la práctica y el trabajo de racionalización diluye, se encuentra en el origen del Derecho Constitucional”. Rousseau (2002) pp. 26-27.

55 Por ejemplo, ver FALlon (2008) pp. 1701-1704.

56 De esta manera, por ejemplo, podría citarse el escepticismo de J. Madison acerca de las motivaciones de las diferentes facciones. Este escepticismo le fue útil a Madison para elaborar las bases de un sistema que considera
} 
ciando la desprotección de los derechos de las minorías por parte de la voluntad mayoritaria $^{57}$.

Por otra parte, una respuesta empírica podría sostener que los desacuerdos morales varían de una sociedad a otra, tanto en sus materias como en su importancia, lo que depende de factores tales como la homogeneización de la sociedad. Una sociedad católica (Irlanda, por ejemplo) tendría mucho menos interés en debatir sobre el aborto que una sociedad más pluralista (la norteamericana, por ejemplo), ya que en esta última la discusión social en torno a la materia se encuentra mucho más acentuada. Los desacuerdos sociales operan de manera diferente, y ellos podrían ser reorientados ${ }^{58}$. Pese a ello, Waldron parece suponer que el debate democrático en torno a la justicia constitucional se centra exclusivamente en materias ampliamente discutibles, en circunstancias que dicha discusión no es necesariamente universal.

Otra manera de elaborar una respuesta empírica dice relación con que, si bien Waldron da razones persuasivas para cuestionar la justicia constitucional atendido cierto contexto, el autor no demuestra la sociedad estaría mejor en la ausencia de un sistema de revisión judicial de las leyes ${ }^{59}$.

A través de la (2) contrarrespuesta democrática, podría discutirse la concepción de Waldron sobre la democracia. Incluso, podría argumentarse que dicha concepción es limitada, y muy discutida. Atendido que la objeción de Waldron a la revisión judicial de las leyes es dependiente de una concepción específica de democracia, y se demostrara que dicha concepción es equivocada (o que adolece de serias falencias), entonces su objeción a la justicia constitucional sería, también, errónea. Bajo esta visión, podría concederse que la revisión judicial es contraria a una versión concreta sobre el sistema democrático, pero no contra toda forma democrática. Esta respuesta obliga a Waldron a defender su concepción y a demostrar que ella es mejor que las otras que están disponibles en la literatura.

Por consiguiente, debemos preguntarnos ¿cuál es la concepción de Waldron sobre el sistema democrático? Se trata de una versión que descansa en el poder de las mayorías. Así (en términos similares a autores como Robert Dahl ${ }^{60}$ ), Waldron cree en una democracia de mayorías, cuantificable en sufragios igualitarios ${ }^{61}$. De esta manera, el control constitucional opera como un mecanismo contramayoritario. Si se cree, a diferencia de Waldron, que el

muchas instituciones contramayoritarias, basadas en los frenos y contrapesos (checks and balances). La justicia constitucional ocupa un lugar especial dentro de ese engranaje. Ver el ensayo de El Federalista $N^{\circ} 10$ (1787), y el No 51 (1788). Ver Cooke (1961).

57 A modo de ejemplo, ver un estudio crítico sobre el parlamento de Nueva Zelandia, en relación con la protección de los derechos de las minorías. Charters (2006).

58 Véase por ejemplo a EstLund (2000).

59 POSNER (2000) pp. 582-592.

60 DAhl (1991). No debe sorprendernos, en consecuencia, que este politólogo arribe a conclusiones similares sobre la justicia constitucional, como ya se señaló.

61 Waldron tiene una visión numérica del sistema democrático, el que es percibido como la suma de preferencias individuales dentro de una sociedad. Para el autor, la democracia requiere ser vista como técnica Waldron (1999-A) p. 107. Este punto es, sin embargo, discutible, ya que (en palabras del propio Waldron), Waldron no cree en una democracia que siga método "cara o sello" (the coin-tossing method) WALDRON (1999-A) p. 113. El autor cree que los dilemas morales deben resolverse a través de la regla mayoritaria. 
sistema político requiere más que una regla de mayoría, entonces sería fácil elaborar una defensa de la revisión judicial sin acusar al mismo de ser contrario a la democracia ${ }^{62}$. Esta creencia, no obstante, requeriría de una versión diversa de democracia ${ }^{63}$, como ocurre con las proporcionadas por J. Habermas ${ }^{64}$, J. Cohen ${ }^{65}$ o por el propio R. Dworkin ${ }^{66}$.

A través de la (3) respuesta legalista, es posible señalar que la teoría jurídica y de la interpretación de que se sirve Waldron puede conducir a un entendimiento erróneo acerca de cómo la justicia constitucional funciona o, a lo menos, acerca de la manera en que debiera operar. Si se usa una teoría diversa, entonces el argumento del autor requeriría de una reformulación. Esta respuesta legalista puede ser formulada de dos formas: (3.1) usando una teoría diferente acerca de cómo el control constitucional funciona (o debiera funcionar) dentro de la tradición anglosajona; o (3.2) usando una perspectiva diferente a la anglosajona $^{67}$.

En primer lugar (3.1), se podría asumir que, reemplazando la teoría constitucional de Dworkin ${ }^{68}$ (que es la que critica del autor) por otra tesis alternativa, la objeción de Waldron podría perder fuerza y debiera, probablemente, ser objeto de una reformulación. La validez de la objeción democrática dependerá, entonces, de la veracidad de la teoría jurídica elegida. En segundo lugar (3.2), se podría sostener que la crítica de Waldron no sería operativa en el contexto de una tradición jurídica diferente.

Creo que la objeción a la revisión judicial de las leyes no funciona completamente en la tradición del derecho europeo continental (en adelante, la tradición del derecho civil) debido a las diferencias existentes. Sostendré que el debate democrático podría tener un espacio bajo ciertas condiciones ${ }^{69}$, lo que, sin embargo, no será equivalente a la profunda discusión existente en la tradición anglosajona. Propondré un marco para aceptar o rechazar el argumento de Waldron en los países del derecho civil.

Evaluaré si las palabras de Dworkin acerca de la "vieja, cobarde y mala filosofía" (citada en la nota introductoria) sobre los jueces aplicando el Derecho, tiene alguna cabida dentro de nuestra tradición. Sostendré que, si Dworkin está en lo cierto, entonces la tradición del derecho civil está cerca de ser una vieja, cobarde y filosóficamente deficiente cultura jurídica. Pero como probablemente Dworkin no está pensando en la tradición europeo

62 La objeción democrática al argumento contrario al control constitucional no es nueva. En efecto, ella fue planteada hace muchos años por Freeman (1990). Este autor sostuvo que el argumento contra a la revisión judicial de las leyes descansa en una premisa mayoritaria de la democracia que no reconoce otras definiciones válidas del término, tales como los derechos fundamentales. Esta crítica ha sido respondida por WALDron (1994).

63 Véase un examen de esta discusión en Michelman (1999).

64 Habermas (1996).

65 Cohen (1989).

66 Dworkin (1996) pp. 21-29.

67 Por ejemplo, véase el trabajo del académico italiano, Mauro Cappelletti, quien se refiere a la material dentro del contexto europeo. Cappelletti (1986).

68 Véase especialmente Dworkin (1996) pp. 1-38.

69 La controversia acerca de la legitimidad del control constitucional existe en la tradición del derecho civil entre muchos académicos. Famoso es el ya clásico debate entre Carl Schmitt y Hans Kelsen sobre él. Véase un examen de dicho debate en Fix-Zamudio (1999). Además, véase el famoso trabajo de Kelsen (1928 edición traducida en 2008). 
continental, diferentes teorías deberían ser integradas al estudio, lo que en definitiva quita fuerza al argumento de Waldron.

Es cierto que el propósito de Waldron se reduce al contexto anglosajón, por lo que alguien podría reclamar que estoy intentando extender algo que él probablemente no acogería. Sin embargo, como en los países de la tradición del derecho continental europeo la discusión democrática también tiene lugar (incluso haciendo referencias a Waldron), es importante elaborar un marco que diferencie el nivel en que el debate puede tener algún asidero.

\section{ACERCA DE LA OBJECIÓN LEGAL AL ARGUMENTO DE WALDRON}

Ya adelanté que el modelo de control constitucional que Waldron critica es el de Dworkin, específicamente aquel por el cual la constitución debe ser interpretada (o "leída", en sus palabras) de acuerdo a "principios morales sobre decencia política y justicia"70. En este apartado demostraré que el argumento de Waldron pierde cabida debido a las limitaciones que ofrece la teoría de Dworkin, la que encuentra debilidades que aconsejan explorar la validez de aceptar teorías alternativas.

Dworkin niega la validez del ataque realista al Derecho con pragmatismo, integrando al sistema jurídico con principios morales. Derecho y moral son, entonces, cuestiones que trabajan juntas (por eso Dworkin es enemigo del positivismo legalista). Reconoce que la moralidad política es incierta ${ }^{71}$, y que "las convicciones políticas y morales [de la persona del juez] afectan inevitablemente las sentencias judiciales" ${ }^{\prime 2}$. Esto es una realidad empírica acerca de cómo el sistema jurídico opera ${ }^{73}$, y reconocer esto significa ser inmunes frente a las objeciones de legitimidad y, también, frente a versiones formalistas que entienden que el rol de los jueces es aplicar el Derecho ${ }^{74}$. El Derecho no es solo aplicar reglas escritas, sino que aplicarlas ideológicamente, de acuerdo a un ejercicio moral y racional de interpretación.

Dworkin cree que su teoría es compatible con la democracia, ya que él sigue una concepción substancial de la misma, basada más en los resultados de las decisiones que en la manera en que dichas decisiones son adoptadas ${ }^{75}$, a diferencia de Waldron, quien dignifica el procedimiento mayoritario para arribar a la decisión ${ }^{76}$.

\footnotetext{
70 DWORKIN (1996) p. 2, p. 7.

71 Dworkin (1996) p. 2.

72 Dworkin (1996) p. 284.

73 Los jueces "no tienen una opción real más que hacerlo". Dworkin (1996) p. 3.

74 Dworkin (1996) p. 12-13. Él también dedica capítulos enteros a argumentar en contra de perspectivas conservadoras del Derecho, especialmente las originalistas y textualistas. Véase, por ejemplo, el capítulo 13 de DWORKIN (1996).

75 Dworkin (1996) p. 7, pp. 15-19, p. 34. Él rechaza la incompatibilidad entre democracia y constitucionalismo en Dworkin (1996) pp. 21-26. "Debemos dejar la premisa mayoritaria aparte, y con ella la concepción mayoritaria de la democracia. No es una concepción defendible acerca de lo que una verdadera democracia es, y no es la concepción norteamericana”. Dworkin (1996) p. 31.

76 Aunque los dos aparecen con un fuerte compromiso en favor de la participación política como elemento configurador del sistema democrático. El problema es que Waldron no propone una manera de defender la vigencia de dicho elemento. Véase Dworkin (1996) p. 24 y WALDron (1999-A) capítulo 11.
} 
Para Dworkin, los jueces no tienen una fuerte discreción judicial, ya que ellos están vinculados por principios, pese a que debe reconocerse que dichos jueces no son aplicadores mecánicos de dichos principios (no podrían serlo). El problema nace cuando se analiza un caso específico en Derecho Constitucional, donde los mismos principios pueden conducir a resultados múltiples y probablemente opuestos. Es en este nivel donde los jueces se ven obligados a elegir un resultado dentro de varias alternativas razonables. Inevitablemente el juez tendrá altos niveles de discreción y creará una regla para responder en el caso concreto. Para Dworkin, esta situación no es necesariamente negativa, ya que el poder de dichos jueces se encuentra restringido por dos cuestiones: lo que el legislador ha dicho (el texto normativo) y el precedente judicial ${ }^{77}$. El precedente responde a la exigencia de lo que Dworkin llama "integridad constitucional”, lo que se complementa con otra teoría del mismo auto: la teoría de la "novela en cadena" (chain novel theory), la que se explica con la metáfora siguiente: estudiar el precedente es como leer una novela escrita por un grupo de autores en serie. La acumulación de los diversos capítulos servirá para entregar certeza y disciplina al Derecho, al restringir la discreción de los jueces-novelistas obligándoles a revisar la totalidad de la historia para arribar a la decisión correcta en el caso concreto ${ }^{78}$. No olvidemos que Dworkin cree que todos los problemas tienen una única (o una mejor) respuesta jurídica.

Como el mismo Dworkin reconoce que las restricciones al poder de los jueces no son absolutas y dejan un margen al intérprete, el mismo autor sugiere que ellas no eliminan el impacto de decisiones honestas y motivadas por convicciones personales ${ }^{79}$.

Las consecuencias de la teoría de Dworkin a la interpretación constitucional pasan por la aceptación de un fuerte poder de revisión judicial sobre la legislación democrática, entendiendo que las decisiones judiciales son definitivas debido al precedente, e incluso aceptando la validez de la creación jurisprudencial de derechos constitucionales no enumerados en la constitución ${ }^{80}$. La jurisprudencia se convierte, entonces, en fuente directa de la constitución.

El modelo de Dworkin es consistente con un juez poderoso, que tiene independencia y no rinde cuentas a nadie, capaz de crear Derecho y vincular a toda la comunidad con su creación normativa, incluso cuando elimina decisiones adoptadas durante el proceso democrático (como los jueces federales en los EE.UU.). ¿Tiene razón Waldron cuando, en un debate de autoridad sobre quién toma las decisiones en un contexto de desacuerdos sociales, critica el poder de este tipo de jueces?

A mi juicio, Waldron tiene un buen argumento contra un modelo constitucional donde la supremacía constitucional se confunda con la supremacía judicial (como en el modelo de Dworkin). Como la Carta Fundamental es rígida y resulta difícil modificarla, la idea de la supremacía judicial obstruye la política parlamentaria cuando jueces constitucionales han dado respuestas previas. Con ello, podría nacer algún tipo de oligarquía de jueces

77 DWORKIN (1996) p. 10.

78 DwOrkin (1986) pp. 228-244.

79 DwORKIN (1996) p. 37.

80 DwORKin (1996) capítulo 3. 
no electos. Si lo anterior es cierto, entonces la crítica de Waldron es acertada. El problema de dicha crítica es el modelo que supone (el de Dworkin). Waldron restringe el ámbito en que su argumento puede ser aplicable cuando decide no hacerse cargo de otras teorías diversas, como las desarrolladas en los países que pertenecen a la tradición del derecho civil a propósito de los tribunales constitucionales (volveré sobre esta materia), y a otras versiones de la teoría del Derecho y de la Constitución presentes incluso en la literatura jurídica norteamericana.

Como R. Fallon ha señalado refutando a Waldron ${ }^{81}$, no es necesario elegir entre dos poderes estatales diferentes para esclarecer quién toma la decisión. El mejor modelo requiere que instituciones diversas trabajen de manera conjunta. Waldron utiliza una falacia de "todo o nada" ("blanco o negro") cuando plantea el problema relativo a determinar quién debe tener la capacidad normativa para tomar una decisión final. Con ello, impide la posibilidad de que un sistema de frenos y contrapesos provoque un diálogo jurídico-político entre los representantes del Derecho (jueces, abogados, académicos, agencias, etc.) y de la política (parlamentarios, ministros de Estado, dirigentes de partidos políticos, etc.). No existen buenas razones para dar un punto final a este diálogo debido a que resulta saludable para la democracia que no se extraigan materias de discusión del proceso político.

Ello no es incompatible con el sistema político norteamericano, y prueba de lo anterior es la evolución que ha tenido la cláusula constitucional de la igualdad en materias de discriminación racial. La sociedad evolucionó de aceptar la esclavitud dentro de la protección de la propiedad privada y de no considerar a los afroamericanos como ciudadanos capaces de entablar acciones judiciales ${ }^{82}$, hasta considerar a los mismos dentro del ámbito de protección de la constitución ${ }^{83}$. Sin embargo, aún no se terminan de discutir los problemas relacionados con políticas públicas de inclusión racial (como la acción afirmativa, entre otras). El problema está lejos de llegar a término, pero ciertos acuerdos sociales y constitucionales relevantes han ido fijando pautas importantes para la discusión, como la eliminación de la doctrina "separados pero iguales" (separate-but-equal doctrine), que permitía defender la existencia de diferencias en el trato jurídico a una raza u otra aún en un contexto de libertad ${ }^{84}$. Las cortes, el congreso y los movimientos sociales han colaborado en modelar el tipo de debate necesario para avanzar en estas materias. Antes de preguntarse quién debe cerrar el debate, hay que preguntarse lo siguiente: ¡es necesario que el cierre del debate?

A lo anterior, podría contestarse que no es posible la existencia de diálogo entre el Derecho y las preferencias políticas, ya que nadie representa fielmente al Derech ${ }^{85}$. Lo

\footnotetext{
81 Véase el trabajo en Fallon (2008).

82 Así lo reconoció la Corte Suprema en Dred Scott v. Sandford, 60 U.S. 393 (1857).

83 Lo que ocurrió con la reforma constitucional que introdujo la XIV enmienda en 1868.

84 La Corte Suprema había defendido la doctrina "separados pero iguales" en Plessy v. Ferguson, 163 U.S. 537 (1896). Dicha doctrina finalizó con la famosa sentencia Brown v. Board of Education, 347 U.S. 483 (1954).

85 Hay varios académicos vinculados a los estudios realistas del derecho que han intentado mostrar de qué manera el Derecho se confunde con la ideología. Por una parte encontramos a los autores pertenecientes al movimiento de Critical Legal Studies (como Duncan Kennedy y Roberto Mangabeira Unger) y por otro a cientistas sociales que han estudiado el comportamiento de los jueces de una manera científica (como Segal y Spaeth). Véase Unger (1986) y Segal y Spaeth (1993).
} 
anterior no es exacto. Podrá concederse que las preferencias personales de los actores jurídicos juegan un rol, pero no es el único. La interpretación del Derecho no se relaciona solamente con las convicciones, sino que con el tratamiento de fuentes jurídicas. Los jueces, entre otros, están vinculados por el uso de documentos jurídicos y obligados a motivar sus decisiones utilizando los mismos. Además podemos pedirle a los actores legales que sean coherentes y, aunque sea cierto que una misma fuente jurídica pueda permitir la inferencia de conclusiones múltiples y opuestas ${ }^{86}$, ello no elimina el hecho de que el lenguaje legal sea usado de manera imperativa. El uso de ese lenguaje dentro de una comunidad jurídica implica la aceptación de ciertos consensos que orientan el debate y restringen la extensión de los argumentos. A veces, por lo demás, el texto normativo proporciona respuestas directas, y no solo principios amplios y de ambigua interpretación. Y cuando los poderes creadores del Derecho (legislativo, constituyente, reglamentario) no han querido solucionar un problema de manera precisa, es lógico entender que existe un ánimo de que dicho conflicto sea resuelto por los jueces utilizando dichos principios. Hay veces en que no existe un texto que disponga de manera directa, pero sí de una dogmática jurídica que hace más predecible lo que pueda ocurrir en tribunales ${ }^{87}$ y de arreglos institucionales que incentivan el respeto por el Derecho, como la posibilidad de que se publiquen las disidencias judiciales (lo que explicaré más delante), la obligación de motivar las decisiones, y la existencia de mecanismos de impugnación de decisiones judiciales, entre otras.

Volvamos a la pregunta: ¿es necesario, en este contexto recién descrito, que se cierre el debate a través de una respuesta definitiva? Cualquier teoría sobre el Derecho que desee ser reconocida dentro de un sistema democrático no puede eludir responder a esta pregunta.

Las teorías alternativas a las de Dworkin, como se verá, en realidad se asocian a maneras diferentes de interpretar la constitución, las que influyen en la teoría del Derecho que se elija en definitiva. Hago presente que no es necesario que todos aceptemos una misma teoría del Derecho para que la justicia constitucional y la democracia puedan operar de manera conjunta y coherente. Sin embargo, a lo menos, es necesario que todos aceptemos teorías del Derecho compatibles con ambas ideas. Una alternativa es el "departamentalismo", que sitúa a las diferentes funciones estatales en un plano equivalente en el contexto de un sistema de frenos y contrapesos, y a este se le suman las teorías de interpretación constitucional (que revisaré brevemente) y que, en general, tienden a reducir la discrecionalidad de los jueces y a disminuir la fuerza de sus decisiones.

Por otra parte, y como se indicó, Dworkin valora la idea del stare decisis (precedente) como una manera de restringir el poder de los jueces. En ese sentido, el precedente vincula los casos futuros para que las sentencias sean más predecibles y más jurídicas. Los supuestos de Dworkin, sin embargo, no son completamente correctos.

Los casos constitucionales pueden ser decididos por cualquier juez norteamericano, aunque el tribunal más importante es la Corte Suprema federal (la "Corte"). Mediante sus

86 En este sentido, véase el trabajo ya clásico de RADin (1925) pp. 357-362, quien muestra de qué manera la utilización de diversas herramientas interpretativas puede llevar a conclusiones diferentes.

87 Véase el argumento de Zapata (2008) pp. 38-45. Véase una crítica a la doctrina nacional en AldunATE (2001). 
sentencias, y utilizando el precedente, la Corte vincula a todos los jueces del sistema judicial; las sentencias de los tribunales inferiores citan los fallos de la Corte; los libros y artículos de derecho constitucional comentan las decisiones de la Corte; las clases de derecho son acerca de la posiciones de la Corte; el diseño de nuevas políticas públicas requiere del análisis de la jurisprudencia de la Corte e incluso los comentarios de Dworkin frecuentemente se entregan con ocasión de fallos de la Corte. Todo el derecho constitucional (o la mayoría) es acerca de la Corte. Luego, para revisar si Dworkin está en lo cierto acerca del precedente y de su descripción de la realidad, debe examinarse la manera en que dicha Corte trata el precedente. La respuesta es problemática para Dworkin.

En efecto, Stephanie Lindquist y Frank Cross han demostrado que, a un cierto punto, la acumulación de precedentes entregará a los jueces mayor discreción ${ }^{88}$, ya que habrá mayores alternativas (sentencias) para seleccionar el Derecho aplicable al caso. Esto pone en duda la eficacia del precedente, aunque no la elimina por completo.

Frente a ello, útil es examinar el comportamiento de los jueces disidentes. Si se considera que el precedente es vinculante al nivel de la Corte, y se considera que el mismo se constituye mediante los votos de mayoría (la sentencia, en estricto sentido) se concederá que existe la obligación para los disidentes de un caso de modificar su manera de votar en controversias jurídicas similares en el futuro. Jeffrey Segal y Harold Spaeth, revisando la evidencia proporcionada por el seguimiento de sentencias de importancia para la doctrina jurídica (landmark cases), han demostrado que los disidentes no modifican sus votos para ajustar su comportamiento al precedente ${ }^{89}$. Concluyen que los jueces suelen mantener sus posiciones, sin importar los efectos del stare decisis. Asimismo, existen muchos acadé$\operatorname{micos}^{90}$ que desaprueban la idea de que exista la institución del precedente al nivel de la Corte $^{91}$. ¿Cómo van a estar vinculados por el precedente los jueces de la Corte Suprema si ellos mismos no lo respetan? Esta duda solo se plantea respecto de la Corte Suprema, y no alcanza necesariamente a la disciplina que muestran los tribunales inferiores respecto del seguimiento de las sentencias de la propia Corte Suprema.

Descartada la posibilidad de que el precedente (a lo menos a nivel de Corte Suprema) sea completamente eficaz para restringir la discrecionalidad de los jueces, revisemos la capacidad que muestran las teorías de la interpretación constitucional para hacer más predecibles las decisiones judiciales futuras. Dichas teorías pueden ser agrupadas en dos: (1) la

\footnotetext{
88 Lindquist y Cross (2005).

89 "El 90,8\% de los votos se conforman con las preferencias reveladas de los jueces. Esto es, solo el 9,2\% del tiempo un juez cambia a la posición establecida en el precedente” Segal y Spaeth (1996) p. 983.

90 Como Barry Friedman y Frederick Schauer, por ejemplo. Para Friedman "Dentro del mundo del Derecho y de las instituciones legales, pocos creen seriamente que los jueces de la Corte Suprema están restringidos en la manera que algunos modelos de Derecho sobre el sistema legal demandan. Casi por definición los casos que la Corte selecciona deberían ser los suficientemente originales para que el precedente [...] no resuelva el caso". Friedman (2006) p. 265. Véase también a Schauer (2000).

91 Este argumento solo es aplicable para el precedente horizontal al nivel de la Corte Suprema, y no es necesariamente aplicable al precedente vertical que vincula a las cortes inferiores. "Mientras que la adherencia al precedente es obligada por la fuerza para el respeto que las cortes inferiores deben guardar sobre las decisiones de las cortes superiores, los argumentos normativos apoyando el stare decisis son menos claros cuando se trata del respeto de la Corte Suprema por sus propios precedentes". Segal y Spaeth (1993) p. 971.
} 
teoría de la "constitución viviente" (the living constitution); y (2) la teoría del originalismo y textualismo.

La primera (1) se relaciona con las ideas de algunos académicos y jueces liberales que creen que la Constitución contiene significados dinámicos, y es vista como un documento vivo que evoluciona de acuerdo a las necesidades de la sociedad ${ }^{92}$. Esta teoría puede servir para modelar una sociedad democrática si la palabra del juez no es final. Si las sentencias judiciales son finales, entonces Waldron tendrá un fuerte punto en contra de esta teoría. Sin embargo, incluso si se acepta la validez de esta teoría sin aceptar la supremacía judicial, Waldron tendrá un argumento en contra de la excesiva discreción judicial que esta tesis conlleva. Toda la teoría de la constitución viviente descansa en la inexistencia de un elemento de interpretación específico que los jueces deban utilizar. Así, la Constitución viviente es una teoría acerca de cuáles son los resultados a los que la interpretación deba llegar. En ese sentido, un uso caótico de herramientas de interpretación jurídicas y fuentes sería aceptable si dichos resultados son conseguidos. Lo anterior resulta problemático si nuestra preocupación es la discrecionalidad judicial. Con todo, y aun considerando los problemas existentes con la tesis de la Constitución viviente, ella al menos es una teoría jurídica sobre el Derecho. Y como teoría jurídica, si ella logra imponerse con integridad y consistencia, podría presentar una buena respuesta a la crítica de Waldron.

La segunda teoría de la interpretación constitucional (2) es una combinación entre originalismo y textualismo, y ha sido defendida, en general, por académicos y jueces conservadores ${ }^{93}$. Existe una desconfianza en el uso del precedente en materias constitucionales cuando estos se oponen a la historia de la constitución o a su letra ${ }^{94}$, por lo que el precedente no siempre debe utilizarse ${ }^{95}$. En cambio, los originalistas y textualistas proponen interpretar la Constitución de la manera en que ella fue creada, para extraer de su proceso de generación y de su texto el real significado de sus cláusulas. Quienes defienden esta teoría son muy críticos de la indeterminación a que llega la escuela de la Constitución viviente ${ }^{96}$, y proponen restringir el poder de los jueces mediante le sentido original (original meaning) de la Constitución. Con esta teoría, crece la visión de los jueces como aplicadores del Derecho, y decrece la visión de los jueces como creadores del Derecho.

Sin perjuicio de que una visión extrema de esta tesis pueda ser acusada de excesivamente formalista, ingenua, y probablemente cínica, debe reconocerse que ella proporciona una teoría consistente con fuertes bases, y a que existe un esfuerzo significativo por eliminar la excesiva discrecionalidad de los jueces a través de medios concretos (texto e historia).

92 El término "living constitution" se le atribuye a Howard Lee McBain, quien habría popularizado el mismo a través de su libro. Véase Mcbain (1927). Véase, entre algunos trabajos que pertenecen a esta escuela, a AcKerMAN (2007) y a STRAuss (2010).

93 Véase, por ejemplo, los famosos trabajos de Scalia (1998) y Bork (1990).

94 Gary Lawson incluso ha sugerido que el precedente es inconstitucional en materias constitucionales, y que no debería utilizase. Lawson (1994) y Lawson (1996). Véase otra crítica en contra del precedente constitucional en Bork (1990) pp. 155-159.

95 Debe tenerse presente que existe una razón pragmática para que conservadores defiendan esta tesis: la intención de eliminar los precedentes de la Corte Suprema que presidió Earl Warren, probablemente el período más liberal de la Corte.

96 Véase, por ejemplo Scalia (1998) pp. 41-44. 
El problema frente a ello es que existen ciertas preguntas que nunca encontrarán respuestas directas en la historia o en el texto ${ }^{97}$ y que (como el mismo Scalia reconoce) "existe mucho espacio para controversia en torno a cuál era el significado original"98. Scalia responde a este problema diciendo que "el originalista al menos sabe qué es lo que está buscando"99. Tal vez el originalista no tenga todas las respuestas, pero tendrá muchas. El problema, entonces, se traduce en la existente incertidumbre respecto de aquellos casos en que la Constitución de verdad no dice nada ${ }^{100}$. ¿Habrá que ser deferentes con la autonomía del legislador? Probablemente sí. La Constitución no aspira a regularlo todo, por lo que la integración de una omisión constitucional será siempre problemática.

Ambas teorías (de la Constitución viviente y del originalismo) tienen problemas y no han estado exentas de críticas. Sin embargo, ambas son teorías jurídicas que tienen el potencial de modelar la discusión legal en el contexto de desacuerdos sociales. Es probable que un fuerte compromiso con alguna de estas teorías no pueda asegurar por sí sola la elusión de la excesiva discrecionalidad que Waldron repudia en materias constitucionales, pero al menos ayudará a exigir integridad y consistencia en la argumentación jurídica. En mi opinión, la existencia de una teoría jurídica consistente y respetada, combinada con la presencia de adecuados arreglos institucionales, puede responder satisfactoriamente las preocupaciones de Waldron.

Sin perjuicio de lo anterior, debe valorarse la objeción democrática, ya que (independientemente de si es cierta o no) la existencia de dicha objeción presiona a los diferentes actores legales a (1) entregar fuertes razones jurídicas que justifiquen sus decisiones; y (2) a mostrar coherencia entre las sentencias dictadas por el mismo órgano (o jueces). Al final, la existencia de la objeción hace que los jueces presten más atención al debate público y su actuar sea, en definitiva, más transparente.

\section{REVISANDO LAS REGLAS EN QUE EL DEBATE DEMOCRÁTICO SE SITÚA}

En este apartado demostraré que el debate sobre la legitimidad democrática de la justicia constitucional tiene menos espacio cuando existen reglas que definen de manera diferente el sistema político y jurídico, sobre todo cuando ellas cambian la perspectiva que se tiene sobre el rol de los jueces. Si se separa la idea de la supremacía constitucional de la idea de supremacía judicial, y se entiende que los jueces tienen un rol no definitivo en la interpretación de la constitución, entonces el debate democrático debiera reenfocarse. Lo anterior cobra fuerza cuando los tribunales constitucionales gozan de diversos arreglos institucionales que los acercan más a un control político y a reglas de transparencia que colaboran con la legitimidad de los mismos.

Dividiré esta sección en dos partes: en primer lugar (4.1) mostraré algunos ejemplos de diseños institucionales tomados de algunos países que siguen la tradición anglosajona (todos

\footnotetext{
97 Véase Lawson (1996) quien intenta entregar una receta para originalistas que están frente al problema difícil de resolver de acuerdo al sentido original.

98 Scalia (1998) p. 45.

99 Scalia (1998) p. 45.

100 Véase Bork (1990) pp. 165-166.
} 
compatibles con la tradición del derecho civil); y en segundo lugar (4.2) mostraré de qué manera el debate se modifica en el contexto de países del derecho civil, especialmente en Chile.

\subsection{Arreglos institucionales tomados de países anglosajones}

Revisaré algunos ejemplos de diseños institucionales que reducen el ámbito del debate sobre la legitimidad democrática de la justicia constitucional. Sin perjuicio de que todos ellos están tomados de sistemas políticos que se insertan en la tradición legal anglosajona, no existen razones para sostener que los mismos son incompatibles con la tradición del derecho civil. Los ejemplos que describiré son complementarios a un punto central que traté en la sección anterior: el uso de teorías de interpretación y una noción del poder de los jueces (no final, sino paralelo) que permitan armonizar el control constitucional con la existencia de un debate público libre.

El primer ejemplo es el uso de disidencias dentro de tribunales colegiados. Como se verá, la existencia de disidencias permite influenciar a los jueces para que ellos apliquen más el Derecho (o los consensos acerca de lo que el Derecho es) y menos sus convicciones personales. Este ejemplo no es obvio, ya que existen muchos países que no permiten a los disidentes a publicar sus votos particulares en el documento que contiene la sentencia. Dichos países, como Francia e Italia, por ejemplo, tienen niveles inferiores de transparencia y accountability a nivel judicial ${ }^{101}$ y carecen de la posibilidad de que los disidentes actúen como un elemento moderador de la mayoría, la que cuenta con los incentivos para asumir posiciones más extremas.

En efecto, la existencia de un disidente que amenaza con "denunciar" a una mayoría que no aplica el Derecho, provoca un efecto significativo en la jurisprudencia de los tribunales colegiados ${ }^{102}$. El efecto-denuncia (whistle blower effect) del disidente influye en las posiciones adoptadas por la mayoría, especialmente en la doctrina jurídica que se invoca. Si este argumento es correcto, entonces el Estado de Derecho se fortalece gracias a la publicación de los votos particulares. Frank Cross y Emerson Tiller han proporcionado evidencia demostrando que en las cortes de apelaciones federales de los EE.UU. (son paneles de tres jueces, como las Cortes de Apelaciones chilenas), siguiendo el famoso precedente del caso Chevron $^{103}$, la existencia de disidentes ha hecho a la mayoría judicial más proclive a aceptar la doctrina legal correspondiente, en vez de simplemente seguir una preferencia basada en razones extrajurídicas ${ }^{104}$. Ante la presencia de un "denunciante, la mayoría debe algunas veces rendirse y mantener la decisión judicial dentro de los confines de la doctrina"105.

\footnotetext{
101 Véase Lasser (2004).

102 Fletcher ha sostenido, en un sentido similar, que el disidente tiene el potencial de "mantener (o al menos de tratar de mantener) la honestidad de la mayoría [...]. El disidente puede a veces forzar a la mayoría a considerar hechos que trabajan en contra del resultado que se favorece por la misma mayoría”. FLETCHER (2009) p. 297.

103 Chevron 467 U.S. 837 (1984) es un caso fundamental para el derecho administrativo norteamericano, que entrega deferencia a la interpretación de la ley hecha por la agencia administrativo cuando la ley no ha sido clara o directa en expresar la voluntad del legislador.

104 Cross y Tiller (1998). Richard Posner ha tocado esta material brevemente, pero concuerda con que "el liberal modera a la mayoría conservadora, y el conservador modera a la mayoría liberal”. Posner (2008) p. 33.

105 Cross y Tiller (1998) p. 2159.
} 
Cuando un panel de jueces, por el contrario, está integrado por una totalidad de jueces que pertenecen a una misma corriente de pensamiento (piénsese, por ejemplo, en jueces nombrados por Presidentes militantes del Partido Demócrata), "los jueces verán a la doctrina como un obstáculo menos para fallar de manera política" ${ }^{106}$, y probablemente arribarán a posiciones más extremas ${ }^{107}$. Los resultados del estudio muestran que el denunciante "hace casi el doble de probable que la doctrina sea seguida cuando la doctrina trabaja en contra de una preferencia política partidista de la mayoría de la corte"108.

Cass Sunstein concuerda con las conclusiones de Cross y Tiller, y ha sugerido una inferencia más general: los “jueces son altamente vulnerables a la influencia de sus pares y en un panel de tres jueces de similar tendencia ellos tenderán a irse a los extremos ${ }^{109}$. Sunstein agrega más evidencia, derivada de casos de acoso sexual ${ }^{110}$ y de casos de Derecho Ambiental ${ }^{111}$, concluyendo que la "[d]iversidad de visiones ayuda a corregir errores -independiente de que jueces de un partido u otro tengan o no razón" 112 y que la "existencia de jueces políticamente diversos, y de un potencial denunciante, incremente la probabilidad de que el Derecho sea seguido" ${ }^{113}$.

Podría contraargumentarse que la experiencia muestra la existencia de muchas cortes donde prevalece una única tendencia entre los jueces, y que la posibilidad de que exista un disidente no siempre tiene cabida. La veracidad de este contraargumento dependerá, en parte, del nivel de alternancia en el poder, sobre todo a nivel de Poder Ejecutivo, debido a la enorme influencia del Presidente de la República en los nombramientos.

También podría contraargumentarse que este arreglo institucional solo es aplicable a cortes colegiadas, pero no tribunales unipersonales. Eso es verdad. Sin embargo, la importancia de esta refutación no es tan alta debido a que (a) normalmente las cortes colegiadas son las que uniforman la aplicación del Derecho; (b) normalmente son las cortes colegiadas las que tienen mayores niveles de poder constitucional (como el Tribunal Constitucional en Chile); (c) normalmente las sentencias de los tribunales unipersonales son susceptibles de ser revisadas por una corte colegiada; y (d) a nivel de tribunales inferiores los incentivos que modelan la conducta de los jueces tienden a maximizar cuestiones diferentes de las pre-

106 Cross y Tiller (1998) p. 2170.

107 Richard Posner va más allá, diciendo que es cierto que "las deliberaciones de grupos de la misma tendencia pueda producir una polarización de dicho grupo, resultando en una opinión más extrema que la opinión promedio que los miembros del grupo tenían antes de empezar a deliberar”. Posner (2008) p. 33.

108 Cross y Tiller (1998) p. 2172.

109 Sunstein (2005) p. 166 y pp. 168-169.

110 Sunstein (2005) p. 171.

111 Sunstein (2005) p. 172. Más adelante, Sunstein reconoce algunas excepciones donde las opiniones disidentes no han sido relevantes para moderar las posiciones de la mayoría (casos de pena de muerte y de aborto, por ejemplo), probablemente debido a que se trata de controversias que responden a Fuertes y profundos desacuerdos sociales. No todas las materias están afectas a tal nivel de desacuerdo, y no todos los países encuentran los mismos niveles de desacuerdo en materias específicas tampoco, razón por la cual la relativización del argumento no siempre opera. Sunstein (2005) p. 183.

112 Sunstein (2005) p. 177.

113 Sunstein (2005) p. 185. 
ferencias políticas, las que son solo un elemento más dentro de la ecuación, tal como lo ha propuesto el modelo de comportamiento judicial sugerido por Richard Posner ${ }^{114}$.

Ya tratado el ejemplo de las disidencias, analizaré brevemente algunos arreglos institucionales extraídos de los sistemas políticos de Canadá e India. En ambos casos se han perseguido diseños que buscan posicionar (con mayor o menor éxito) a la justicia constitucional como una función del Estado paralela a las demás autoridades democráticas relevantes. Lo interesante de estos casos, es que demuestran que el argumento de Waldron no opera con igual fuerza en países de tradición anglosajona que tienen modelos de justicia constitucional. Se trata, como se verá, de arreglos institucionales que no se relacionan con la tradición jurídica, sino que con la política.

En el sistema constitucional de la India ${ }^{115}$, las sentencias interpretativas de la constitución no se consideran finales, ya que el legislador tiene la capacidad para reformar la constitución de manera más flexible que en la mayoría de las democracias constitucionales (y, con ello, alterar la interpretación judicial de las normas constitucionales), como ha ocurrido en la práctica ${ }^{116}$. Como las interpretaciones judiciales a la constitución no son finales ${ }^{117}$, ellas pasan a formar parte del proceso político ${ }^{118}$. Gracias a esto, la existencia de una constitución más flexible le quita fuerza a la crítica democrática de Waldron.

La rigidez constitucional vigoriza la estabilidad de la Carta Fundamental, y un procedimiento flexible de reforma a la constitución debilita la supremacía judicial y fortalece la democracia mayoritaria. Ambos bienes (estabilidad y mayoritarismo) se encuentran en una tensión aparente. ¿Existen diseños institucionales que impidan sacrificar uno de ellos en favor de otro? Un ejemplo es el modelo propuesto por la constitución chilena, que cuenta con un proceso de reforma más flexible que el de la constitución de EE.UU. y más rígido que el de la Carta Fundamental india. Otro ejemplo lo proponen A. Hutchinson y J. Colón-Ríos, para quienes las constituciones debieran ser sometidas a revisiones periódicas por asambleas constituyentes. Con ello, argumentan los autores, se superarían las dificultades mayoritarias mediante la permanente participación política de la ciudadanía ${ }^{119}$. Aunque la

114 Posner (1993), ha sugerido un modelo para analizar el comportamiento de jueces. Dicho modelo considera elementos pertinentes a cualquier persona normal, como el placer y el ocio. Este interesante artículo le quita importancia a la ambición política del juez, o a la posición personal que el mismo pueda tener, elementos que solo juegan un rol menor en el trabajo diario del juez.

115 Ver el art. 13 de la constitución de la India (1950), donde se regula la justicia constitucional.

116 Existen tres maneras de reformar la constitución india, dependiendo de la materia. Algunas cláusulas importantes solo requieren de la aprobación de la simple mayoría del parlamente; otras cláusulas requieren de la aprobación de dos terceras partes de los miembros de cada cámara; y otras requieren la ratificación de la mitad de las legislaturas de los Estados (véase el art. 368 de la constitución india). La Constitución ha sido modificada en muchas ocasiones, probablemente debido a lo extenso y detallado de su texto.

117 Debe tenerse presente que, desde el fallo de la Corte Suprema india en His Holiness Kesavananda Bharati $v$. The State of Kerala and Others (AIR 1973 SC 1461), se han declarado inconstitucionales varias reformas constitucionales aprobadas en el parlamento. Ello ha sucedido cuando los proyectos de reforma controvierten la "estructura básica" de la Carta Fundamental. Ver Deva (2010).

118 Ver Jayasurya (2010), quien señala que en India hay una "completa armonía entre la revisión judicial de las leyes y la supremacía parlamentaria”.

119 Hutchinson y Colón-Ríos (2011). 
propuesta de estos autores me parece inconveniente por diversos motivos, ella es otro buen ejemplo de un modelo incompatible con la necesidad de que exista una última palabra.

Un tercer ejemplo es lo que ocurre en el sistema canadiense ${ }^{120}$. La característica más interesante de este sistema (para estos efectos) es la cláusula "a pesar de" (notwithstanding clause) ${ }^{121}$. Mediante dicha cláusula, se permite a la legislatura federal (y también a las legislaturas provinciales) revertir temporalmente una decisión judicial de control constitucional, suspendiendo sus efectos por un período limitado de tiempo. La sentencia queda transitoriamente congelada, hasta que el próximo parlamento competente se pronuncie luego de la siguiente elección parlamentaria. Este parlamento podrá votar a favor de la interpretación contenida en la sentencia, o podrá confirmar la decisión de la legislatura anterior. De esta forma, la sentencia interpretativa de la constitución no es la última palabra ${ }^{122}$. Sin perjuicio de lo anterior, algunos autores se muestran críticos de la manera en que el sistema de justicia constitucional canadiense ha funcionado ${ }^{123}$. Habría que preguntarse si esas críticas permanecerían idénticas en el evento de que el arreglo institucional descrito se instaurara dentro de una tradición jurídica donde los jueces tengan menos poderes que en la anglosajona.

No hay que olvidar que la objeción de Waldron se dirige contra el modelo de revisión judicial de la ley de EE.UU. en la versión de Dworkin. He sostenido más atrás que esta versión no es necesariamente el mejor exponente del constitucionalismo y, por otro lado, he señalado que existen sistemas alternativos al de EE.UU., dentro y fuera de la tradición jurídica anglosajona. Sin embargo, hay que considerar el modelo norteamericano contiene algunos elementos que vigorizan la legitimidad del control constitucional, como ocurre con los elevados niveles de transparencia judicial, participación a través de procedimientos adversariales y la existencia permanente de disidencias judiciales, entre otras ${ }^{124}$. Probablemente, estos elementos no son suficientes para justificar la idea de la supremacía judicial, pero pueden restringir la importancia de la objeción democrática en un sistema que acepte el departamentalismo.

\subsection{LA TRADICIÓN DEL DERECHO CIVIL Y LA OBJECIÓN DEMOCRÁTICA}

En este apartado me pregunto si las diferencias que se observan en la tradición jurídica del derecho civil son o no relevantes para la discusión democrática de la justicia constitucional.

La respuesta depende del cumplimiento de los supuestos de Waldron, ya descritos anteriormente, y de diferentes variables.

\footnotetext{
120 Sobre el debate relativo a la legitimidad de la revisión judicial de las leyes en Canadá, ver Dixon (2009) y Panaccio (2010).

121 Ver la sección 33 del Charter of Rights and freedoms, que forma parte de la Constitución de Canadá.

122 Para una descripción de la cláusula "a pesar de", ver HogG (1984) pp. 297-298.

123 Ver la opinión de Charles Maxime Panaccio, quien sostiene que la preocupación democrática elaborada por Waldron no se satisface con la cláusula "a pesar de". Panaccio (2010) pp. 100-118. Véase también la opinión de Rosalind Dixon, para quien el modelo canadiense ofrece una promesa de diálogo intermedio que deja de lado la idea de la supremacía judicial y, también de la supremacía del parlamento. Sin embargo, Dixon se muestra crítica de que el actual diálogo satisfaga la promesa del sistema. Dixon (2009).

124 Ver, en especial, Lasser (2004).
} 
Un hecho que hace más débil el argumento de Waldron en el contexto de los países del derecho civil es que, en general, el proceso judicial "ofrece monolíticas [...] sentencias colegiadas [...] que evitan la discusión de política pública en favor de silogísticas $-o$ al menos altamente deductivas- declaraciones que moderan, si no maquillan o ignoran, todo significativo trabajo judicial interpretativo" ${ }^{25}$. Con lo anterior, los jueces son exclusivamente responsables por la aplicación (mas no por la creación) del Derecho. Es cierto que esta visión admite matices, ya que es inevitable que, aunque sea en algún grado mínimo, los jueces generen reglas aplicables a los casos concretos, sobre todo cuando resuelven sobre la base de principios. Sin embargo, esta creatividad no alcanza los niveles de la tradición anglosajona, donde los jueces son lawmakers que suelen construir tests o estándares de aplicación general ${ }^{126}$.

Otra diferencia relevante dice relación con el poder de los jueces en relación a los efectos de sus sentencias. Es evidente que la ausencia de efectos expansivos de las sentencias (salvo por algunas sentencias de tribunales constitucionales) y la carencia del stare decisis, reducen significativamente el poder con que ellos actúan ${ }^{127}$. Sus decisiones producen, en general, efectos relativos y son aplicables a las causas concretas, razón por la cual el rol en la creación del Derecho es limitado. La crítica de Waldron se dirige contra un modelo de justicia constitucional basado en el precedente, donde incluso se permite la creación de derechos constitucionales por la vía jurisprudencial ${ }^{128}$. La teoría de Dworkin parece ser incompatible con la noción de ordenamiento jurídico que se utiliza en la tradición del derecho civil, donde se supone que los jueces no son creadores del Derecho ${ }^{129}$. Sin perjuicio de

125 LASSER (2004) p. 4.

126 Es importante considerar que, como los profesores Carter y Burke sostienen, el uso judicial directo del common law entrega a los jueces mucha más discreción que la mera interpretación de textos normativos. En la tradición del derecho civil no existe el uso judicial directo de ese common law, ya que casi toda la labor judicial se centra en la interpretación de las fuentes jurídicas disponibles. Véase CarTer (2004 séptima edición) pp. 36-68.

127 Véase un acercamiento diferente en Merryman y Pérez-Perdomo (2007 tercera edición) p. 47. Para estos autores, el "hecho de que las cortes en la jurisdicción del derecho no actúan diferente en la entrega de sentencias respecto de lo que hacen las cortes en los Estados Unidos [...] hace que la ausencia de una regla formal de stare decisis tenga relativamente poca importancia [...] todos saben que las cortes del derecho civil sí usan precedente". No comparto la visión de estos autores. Si bien las cortes en los países del derecho civil tienden a citar su propia jurisprudencia, y los abogados a argumentar sobre la base de sentencias anteriores, ello dista mucho de ser un equivalente al uso del precedente. El uso del precedente se basa fuertemente en la realización de una analogía entre los hechos de los casos que se traen a colación, en la identificación de la pregunta jurídica correspondiente, y en la evaluación de la aplicación de reglas jurisprudenciales de creación anterior, lo que va mucho más allá del mero ejercicio citar sentencias previas.

128 Dworkin (1996) pp. 76-116.

129 Una visión formalista del derecho anglosajón diría que los jueces no están facultados para crear Derecho, sino que solo para seguir el precedente. Sin embargo, en muchos casos los jueces crean reglas para el caso que son seguidas en el futuro, y esas decisiones son publicadas en reportes oficiales para que la comunidad las conozca. Para la provocativa (pero correcta) perspectiva de Martin Shapiro, los jueces son "mentirosos" porque ellos dicen que están aplicando el Derecho existente en circunstancias que siempre hay un elemento de creación y, por consiguiente, siempre habrá algo de retroactividad. "Las cortes y los jueces siempre mienten. Mentir es la naturaleza de la actividad judicial”. SHapiro (1994) pp. 155-156, p. 156. 
lo anterior, y tratándose de los modernos tribunales constitucionales, la tradición jurídica del derecho civil anota ciertos matices.

Estos tribunales constitucionales han evolucionado y se han apartado del clásico modelo propuesto por Hans Kelsen ${ }^{130}$, que fuera implementado por primera vez en la Constitución austríaca de 1920 (o 1930, su validez no fue inmediata) ${ }^{131}$. Si bien muchos países siguieron inicialmente este modelo (como Italia, Alemania, España y varios países latinoamericanos), algunos siguieron caminos paralelos, como Holanda, que carece de justicia constitucional. El caso de Francia es interesante, ya que (apartándose del modelo kelseniano) es una muestra acerca de cómo el formalismo propio de la tradición del derecho civil y la sacralización de la ley ${ }^{132}$ son capaces de rechazar la idea de una justicia constitucional fuerte (ex post) ${ }^{133}$, a lo menos hasta antes de la reforma constitucional de $2008^{134}$. Por lo mismo, desde la Constitución de 1958, los franceses han diseñado una justicia constitucional (prácticamente preventiva) basada en el Consejo Constitucional, un órgano políticojurídico con poderes limitados y con un sistema de integración de sus miembros que lo hace mucho más sensible a la política democrática ${ }^{135}$. La discusión de la legitimidad democrática está presente en Francia ${ }^{136}$, pero el sistema político ha respondido a esta inquietud de una manera opuesta a la norteamericana.

El modelo kelseniano, en el sentido original, incluía la receta de evitar la utilización de criterios de control constitucional relacionados con principios muy abstractos como

130 Véanse las recomendaciones de Hans Kelsen acerca de los tribunales constitucionales en KeLSEN (1928 edición traducida en 2008).

131 Para examinar las diferencias entre el modelo austríaco y el norteamericano, véase el ya clásico trabajo de Hans Kelsen, en Kelsen (1942).

132 La tradición francesa fue construida bajo la doctrina de la separación de poderes estricta que Montesquieu promovió en "El Espíritu de las Leyes". A ello se le sumaba la idea de la inhabilidad de la ley sostenida por Rousseau en "El Contrato Social". Véase CAppellettr (1986) pp. 10-18. Francia tiene una fuerte tradición basada en las palabras de los códigos, la profesionalización de la judicatura y la desconfianza en los jueces. LASSER (2009) pp. 42-43.

133 Para Favoreu, Francia rechazó aceptar el modelo norteamericano (fuerte de justicia constitucional) debido a (a) la sacralización de la ley basada en la infalibilidad del legislador; (b) la incapacidad del juez ordinario de carrera, tímido y débil; (c) la ausencia de unidad de jurisdicción; y (d) la insuficiente rigidez de la Constitución. FAvoreu (1994) pp. 18-21. Estos argumentos también son aplicables, para Favoreu, a los casos de Alemania e Italia.

134 Véase un resumen de la justicia constitucional francesa basada en el Council Constitutionnel en mi trabajo Verdugo (2010) pp. 205-209.

135 El Council está integrado por nueve miembros que se renuevan parcialmente (un tercio) cada tres años. Tres de ellos son nombrados por el Presidente de la República, tres por el Presidente del Senado y tres por el Presidente de la Asamblea Nacional. Sirven por un tiempo limitado a nueve años. Integran el Council por derecho propio los ex Presidentes de la República (actualmente lo integran Giscard y Chirac), quienes sirven de por vida. Morton ha dicho que este órgano es incluso más político que la Suprema Corte de los EE.UU. Morton (1988). Para Tallon, los miembros de esta institución ni siquiera son jueces. Tallon (1979). Para Bon, esta institución puede ser considerada como una tercera cámara legislativa. Bon (1993) p. 386.

136 Véase un buen ejemplo en Rousseau (2002) pp. 20-31, quien dedica varias páginas al tratamiento del problema en el contexto de la justicia constitucional europea. Debe advertirse que, fuera de Francia, también se ha planteado esta discusión. Véase por ejemplo el argumento del español Eduardo García de Enterría, en García DE ENTERRÍa (2006 cuarta edición, primera edición de 1981) pp. 187-208. 
“justicia” y "libertad"137, ya que, según el mismo Kelsen, ellos incrementarían la discreción de los jueces de una manera "peligrosa"138. La evolución de los tribunales constitucionales (y de los tribunales internacionales europeos ${ }^{139}$ ) siguió el camino contrario y comenzó a utilizar principios abstractos, especialmente aquellos relacionados con los derechos fundamentales. Como Cappelletti reconoce, después de la II Guerra Mundial la justicia constitucional ha creado mecanismos de protección de los derechos fundamentales ${ }^{140}$ e incluso del derecho natural ${ }^{141}$.

Lo anterior se combina a la creciente aceptación del fenómeno de la constitucionalización del Derecho ${ }^{142}$. Si la constitucionalización entrega a los jueces más posibilidades de interpretar principios o conceptos indeterminados o derechos en un sentido amplio, entonces habrá más espacio para inferir soluciones múltiples, alternativas y opuestas, lo que incrementa la discrecionalidad. Si ello es así, entonces la objeción democrática tendrá un espacio.

Sin embargo, hay algunos arreglos institucionales de los tribunales constitucionales que los distinguen fuertemente del sistema de justicia constitucional norteamericano y tienen la capacidad de reducir el espacio de la objeción democrática. Tomaré como ejemplo al modelo chileno actual.

(a) Los tribunales constitucionales no son parte del denominado "Poder Judicial" (pese a que tiene facultades jurisdiccionales). Formalmente, ellos no son superiores jerárquicos de ningún juez, lo que permite focalizar la discusión en un solo tribunal, y no en un conjunto general de cortes. En consecuencia, el tribunal constitucional tiene el monopolio del control constitucional de las leyes, lo que hace que las propuestas para "democratizar" la revisión judicial de las leyes se puedan orientar de manera más sencilla hacia esa institución específica, existiendo una menor probabilidad de dispersión en la interpretación de la Constitución ${ }^{143}$.

(b) No existe el precedente en su variante anglosajona, aunque se suela citar la jurisprudencia pasada, lo que disminuye la importancia de la creación de reglas extraídas de la jurisprudencia. En general, los jueces deben someterse a los fallos del tribunal constitucional solo en aquellas causas particulares que les compete, con la excepción

137 Esto es similar a lo que ocurre con las normas de "textura abierta", idea desarrollada por Herbert Hart. Véase HART (1994 segunda edición, primera edición de 1961) pp. 124-136.

138 Véase Kelsen (1928 edición traducida de 2008) pp. 34-36.

139 Es importante considerar la creciente importancia de tribunales internacionales para los sistemas jurídicos domésticos, sobre todo cuando se considera que la legislación internacional puede producir nuevos estándares de revisión judicial de la ley interna, como ocurre en Holanda.

140 Él habla de la "evolución de los derechos humanos". Cappelletti (1986) p. 30.

141 Cappelletti (1986) p. 31.

142 Sobre la constitucionalización, véase FAVoreu (2001) pp. 31-43. Para una visión crítica, véase CorreA (2009).

143 Ello es sin perjuicio de que existan otras instituciones encargadas de velar por la constitucionalidad de nomas inferiores a la Constitución, como ocurre con la Contraloría General de la República (toma de razón), los tribunales superiores de justicia (recursos de protección), y los tribunales en términos generales (nulidad de derecho público), entre otros. 
de los escasos fallos tienen fuerza derogatoria (los que son obligatorios para toda la comunidad).

(c) No existe la institución del certiorari, esto es, el poder del tribunal para seleccionar discrecionalmente aquellos casos que parezcan más importantes para confeccionar la agenda judicial (con el certiorari no rige la inexcusabilidad). En virtud de ello, el poder del tribunal se encuentra limitado a casos que no puede seleccionar. La agenda del tribunal se constituye por las causas se presentan, aunque el tribunal ejerce cierto grado de control mediante el examen de admisibilidad.

(d) En la tradición del derecho continental europeo (a la que pertenecemos), existe un especial respeto por la doctrina de autores de prestigio. Aunque esto es más frecuente en áreas diferentes a la estrictamente constitucional (especialmente en el Derecho Civil), no puede desconocerse la existencia de una (aunque relativamente nueva) dogmática jurídica elaborada por autores como Alejandro Silva B. Junto con ello, nuestra práctica constitucional manifiesta una tendencia a utilizar el texto de la constitución. En los EE.UU., en cambio, el derecho constitucional práctico no se encuentra en el texto constitucional, sino que en la jurisprudencia.

A lo anterior, se suma la existencia de constituciones con mayor densidad normativa que la norteamericana. Ello vigoriza el textualismo como técnica de interpretación ${ }^{144}$, lo que restringe la tarea creativa de las cortes ${ }^{145}$ y reduce la probabilidad de que los jueces chilenos desarrollen argumentos de política pública. También, cabe hacer presente que los tribunales constitucionales suelen ser menos independientes que los jueces federales norteamericanos (duran menos años en el cargo, sus designaciones no siempre están sujetas a control político, etc.).

Por su parte, el lenguaje de los textos constitucionales no deja de ser relevante. Comparado con la constitución de EE.UU., la Constitución chilena entrega más respuestas normativas en cuestiones donde existen desacuerdos morales, como ocurre con la autorización constitucional de la pena de muerte y con la protección del que está por nacer $^{146}$. En EE.UU., por el contrario, el derecho a abortar emana de la jurisprudencia (que lo encuentra bajo la protección de la privacidad ${ }^{147}$ ), y no resulta muy claro que la pena de muerte sea contraria a la cláusula que prohíbe los "castigo crueles e inusuales" (cruel and unusual punishments). Otros ejemplos que generan controversia son los relativos a la

\footnotetext{
144 Ver, en general, la comparación de Goutal (1976) y Lasser (2004).

145 La capacidad del texto normativo para restringir el poder interpretativo del juez dependerá de los detalles. Mientras mayor sea la densidad de dicho texto, menor será la discrecionalidad que los jueces tendrán. Mientras mayor sea la densidad del lenguaje, entonces, más predecibles serán las sentencias y menos responsables serán los jueces en el ejercicio de sus funciones.

146 Es cierto, sin embargo, que respecto del aborto algunos académicos han interpretado la constitución de una manera diferente, aunque ellos se encuentran en una minoría. Véase, por ejemplo, a FigueroA GARCíAHuidobro (2007). También es cierto que hay incerteza relativa a la legitimidad constitucional de la pena de muerte, aunque esta incertidumbre ha sido provocada no por la constitución, sino que por un tratado internacional. (Pacto San José de Costa Rica).

147 Roe v. Wade, 410 U.S. 113 (1973), sentencia que debe ser complementada con Planned Parenthood v. Casey, 505 U.S. 833 (1992).
} 
protección de los derechos sociales (aunque existan bases textuales en la constitución para su protección) ${ }^{148}$; la prohibición de la censura previa; la prohibición de la esclavitud; y los poderes de la policía para la detención; entre muchos otros. Todas estas materias no son resueltas por la Constitución norteamericana, en la que se encuentran amplias cláusulas que deben ser complementadas por precedentes jurisprudenciales que las delimitan. Para todas estas materias, la discrecionalidad del juez hace que el argumento de Waldron se fortalezca en EE.UU. y se debilite en Chile.

Existen otras materias, no obstante, donde el argumento de Waldron podría fortalecerse en Chile. Ello ocurre cuando se interpretan ciertas disposiciones que contienen conceptos abstractos controvertibles en su interpretación, como ocurre con el bien común, la familia y el principio de subsidiariedad. Sin embargo, algunas de ellas pueden ser complementadas con normas constitucionales que, bajo una interpretación sistemática que integre el texto normativo, delimite su contenido práctico y eventualmente permita disciplinar a los jueces. Ello ocurre, por ejemplo, cuando al concepto de bien común se le agrega el principio de juridicidad en la definición de las necesidades que se pretenden satisfacer; y cuando al principio de subsidiariedad se le complementa con la regulación restrictiva del Estado empresario. Ello probablemente no ocurre tan fácilmente, sin embargo, con el concepto de familia y, tampoco, con la definición del derecho a la honra.

(e) La manera en que el tribunal constitucional se integra es variada. Sus miembros provienen de los principales órganos estatales (Presidente de la República, Congreso Nacional y Corte Suprema), lo que relativiza la importancia del eje conservador/liberal que se aprecia en los tribunales norteamericanos, sin alterar el sistema de disidencias judiciales.

(f) Los ministros del tribunal constitucional duran un término limitado en sus cargos, a diferencia del modelo de los jueces federales de EE.UU. (similar al de los jueces chilenos del Poder Judicial), inamovibles de por vida (en Chile la inamovilidad cesa a los 75 años). Este sistema entrega menos garantías de independencia a los ministros del tribunal y eleva el nivel de accountability ${ }^{149}$. La una tensión entre independencia y accountability es resuelta por el modelo kelseniano de una forma más equilibrada, tal como lo proponía Kelsen en los textos ya citados.

148 Ver algunos fallos del Tribunal Constitucional: sentencia Rol No 976, 26 de junio del 2008, y sentencia Rol No 1710, 6 de agosto del 2010. Acerca de esta discusión, compárense las opiniones de Martínez EstaY (2010) y Figueroa García-Huidobro (2009).

149 La independencia de la Corte Suprema de EE.UU. es más alta que la del modelo kelseniano, lo que no significa necesariamente que ella más leal con el Estado de Derecho. Como dice Robert Cooter, la independencia lleva a los jueces a fallar de manera más libre (con menos costos asociados) de acuerdo a sus preferencias (sea la que entrega el Derecho o sus convicciones personales). Véase CоOTER (2000) pp. 195-198. Los justices de la Corte Suprema están sujetos a un control político ex ante (anterior a que ejerzan sus funciones) y sirven de manera inamovible con altas remuneraciones aseguradas y con bajos niveles de rendición de cuentas (la acusación constitucional es, en la práctica, un instrumento casi en desuso). Por otra parte, la menor duración en el cargo de los ministros de los tribunales constitucionales hace que ellos estén permanentemente sometidos al control político (si existe posibilidad de ser nombrados de nuevo) o sujetos a un control difícil de determinar si ellos no pueden ser reelegidos, caso en el cual su funcionamiento se condicionará por las perspectivas futuras que tenga cada juez en particular. Este último condicionamiento no existe en el caso de los ministros de la Corte Suprema, en atención a la larga duración de sus funciones. 
En Chile la integración del Tribunal Constitucional y los términos limitados a los que se sujetan sus jueces hace que este órgano esté menos aislado de la política que los jueces federales norteamericanos y que los ministros de la Corte Suprema chilena. El Tribunal chileno se compone por 10 ministros: 3 son nombrados por el Jefe de Estado ${ }^{150}$; 3 por son designados por la Corte Suprema; 2 son electos por el Senado, y los 2 restantes son elegidos por la Cámara de Diputados con aprobación del Senado. Como puede observarse, el modelo de integración es representativo de los tres poderes estatales, teniendo mayoría el que tiene niveles de representación más inclusivos: el Congreso.

Estos cinco puntos, comunes a algunas tradiciones del derecho civil que han adoptado alguna forma de tribunal constitucional, hacen que la crítica de Waldron encuentre un lugar más pequeño para ser debatida.

A lo anterior, hay que adicionar dos cuestiones que tienen el potencial de disminuir los costos democráticos de la revisión judicial de las leyes: la idea de auto restricción de los jueces y la posibilidad de que las decisiones judiciales puedan ser revisadas por un parlamento electo.

En el primer caso, los jueces son deferentes con las autoridades democráticamente electas y eluden la declaración de inconstitucionalidad. Esto ocurre, por ejemplo, con aquellas que interpretan la ley que controlan de una manera compatible con la Constitución (sentencias interpretativas). También hay ejemplos en el derecho internacional. La Corte Europea de Derechos Humanos (CEDH) suele utilizar la doctrina del "margen de apreciación", que permite respetar las validez regulaciones domésticas debido a diferencias existentes $^{151}$. Por otro lado, la Corte Suprema de EE.UU. ha elaborado una doctrina por la cual algunas cuestiones que pertenecen a la política no son revisables judicialmente ( $p o-$ litical question doctrine $)^{152}$. Con anterioridad a todo ello, parte de la doctrina norteamericana promovía el denominado self-restraint, tesis popularizada por Thayer a fines del siglo $\mathrm{XIX}^{153}$ que hoy se encuentra presente en la retórica judicial, aunque hay quienes opinan que se encuentra abandonada en la práctica ${ }^{154}$. En Chile, como ya adelanté, P. Zapata ha defendido una tesis similar, que denomina "deferencia razonada".

Todavía es muy pronto para evaluar con precisión la operatividad chilena de esta tesis, ya que ella lleva muy pocos años siendo utilizada. Ella se ha justificado sobre la base de la presunción de constitucionalidad de la ley que se cuestiona, bajo el esquema de respeto

\footnotetext{
150 La evidencia demuestra que estos ministros tienden a ser leales con el Presidente que los nombró. Véase Carroll y Tiede (2010).

151 Véanse, por ejemplo, las siguientes sentencias: Vo v. Francia (2004) CEDH, 8 de julio de 2004; Boso v. Italia (2002) CEDH, 5 de septiembre de 2002; Evans v. Reino Unido (2007) CEDH, 10 de abril de 2007; Tysiac v. Polonia (2007) CEDH, 24 de septiembre de 2007; Open Door and Dublin Well Woman v. Irlanda (1992) CEDH, 29 de octubre de 1992.

152 Sobre las cuestiones políticas no justiciables, ver Baker v. Carr, 369 U.S. 186 (1962); Nixon v. United States, 506 U.S. 224 (1993); Vieth v. Jubelirer, 541 U.S. 267 (2004); y Bush v. Gore, 531 U.S. 98 (2000). Sobre la materia, aplicada al problema de los tratados internacionales, véase mi trabajo Verdugo (2010-A) pp. 79-90.

153 Ver Thayer (1893).

154 Posner (2010). Este autor opina la tesis thayeriana está muerta, ya que (1) ella tiene fundamentos débiles; (2) existen jueces activistas; (3) la influencia de la corte Warren; y (4) la popularidad de teorías constitucionales incompatibles con la tesis de Thayer.
} 
que exige la separación de funciones y la autonomía del legislador electo popularmente. Debido a ello, la deferencia supone una suerte de buena fe del legislador, que asume que este no ha buscado contradecir la Constitución. Por ello, el intérprete debe buscar el sentido que mejor permita hacer compatible la ley con la Carta Fundamental.

Por ejemplo, el Tribunal ha invocado la deferencia para: (a) limitar sus propios poderes de revisión de la legislación debido a razones de texto del precepto que se examina ${ }^{155}$; (b) para eludir la inconstitucionalidad de un precepto contenido en un tratado internacional ${ }^{156}$; (c) para no invadir las atribuciones de otros tribunales (de jueces que no tienen poderes de revisión legislativa $)^{157}$; (d) para no considerar apreciaciones de hecho, especialmente cuando ellas se relacionan con posibles consecuencias futuras difíciles de predecir ${ }^{158}$; (e) para permitir al legislador determinar libremente como fin de una ley la protección de un derecho fundamental ${ }^{159}$; y (f) para responder un reclamo del Presidente de la República, incluso cuando el propio Tribunal indicó que no está obligado a proporcionar respuesta alguna ${ }^{160}$.

Sin perjuicio de lo anterior, el Tribunal Constitucional también ha invocado la tesis de la deferencia (y/o la presunción de constitucionalidad) en sentencias que han declarado la inconstitucionalidad del precepto impugnado ${ }^{161}$, lo que parece contradictorio. En esta clase de fallos, la justificación entregada para fundamentar la deferencia parece confusa, ya que explica como compatibles cuestiones que se encuentran en tensión, como ocurre con el Estado de Derecho, los frenos y contrapesos, el respeto por la decisión mayoritaria y la separación de poderes ${ }^{162}$. A veces estas ideas se contradicen, por lo que resulta difícil entender lo que el Tribunal intenta transmitir. Esto se da especialmente cuando se declara la inconstitucionalidad del precepto legal.

\footnotetext{
155 Véase, por ejemplo, sentencia del Tribunal Constitucional Rol No 626, 16 de enero de 2007, donde la deferencia fue utilizada para limitar el ámbito de operatividad del poder de declarar la inconstitucionalidad, al restringir las palabras específicas que el Tribunal puede declarar inaplicable.

156 Véase, por ejemplo, sentencia del Tribunal Constitucional Rol No 309, 4 de agosto del 2000.

157 La consecuencia práctica de esta declaración es la imposibilidad de declarar la inconstitucionalidad. Véase, por ejemplo: sentencia del Tribunal Constitucional Rol No 503, 19 de julio de 2006; Sentencia del Tribunal Constitucional Rol No 552, 11 de marzo de 2008; Sentencia del Tribunal Constitucional Rol No 706,30 de marzo de 2007; Sentencia del Tribunal Constitucional Rol No 790, 11 de diciembre de 2007; Sentencia del Tribunal Constitucional Rol No 1129, 29 de mayo de 2008; Sentencia del Tribunal Constitucional Rol No 1678, 23 de julio de 2010.

158 Sentencia del Tribunal Constitucional Rol No 136, 26 de noviembre de 2001, considerando 14.

159 Sentencia del Tribunal Constitucional Rol No 1463, 23 de septiembre de 2010, considerando 30. Es importante destacar, sin embargo, que en este caso el Tribunal Constitucional finalmente declaró la inaplicabilidad del precepto legal impugnado, pero por razones diferentes: no fue debido al fin que la ley perseguía, el que fue respetado por el Tribunal.

160 Sentencia del Tribunal Constitucional Rol No 1867, 30 de diciembre de 2010, considerando quincuagésimo primero.

161 Véase, por ejemplo, sentencia del Tribunal Constitucional Rol No 681, 26 de marzo de 2007, especialmente el considerando 7.

162 Sentencia del Tribunal Constitucional Rol No 681, 26 de marzo de 2007, considerando 7.
} 
Todavía es temprano, sin embargo, para inferir conclusiones relativas al uso y contenido de la deferencia, aunque resulte evidente que la confección de la misma anota contradicciones.

Mientras mayor aceptación tengan este tipo de teorías, menor espacio habrá para plantear el cuestionamiento democrático. Sin embargo, estas teorías encuentran problemas importantes, ya que renuncian a (al menos una parte de) la supremacía constitucional y, sobre todo, porque no es fácil definir estándares claros para precisar en qué casos cabe aplicarla y en qué casos no. La falta de definición puede conducir a una aparente arbitrariedad en la selección de casos sujetos a la autorrestricción judicial, lo que, lejos de debilitar la objeción democrática, podría fortalecerla.

Por otra parte, la eventualidad de que órganos democráticamente electos puedan revisar las sentencias judiciales es una forma de destruir la idea de la supremacía judicial, lo que trae de vuelta la discusión al proceso político libre. Ejemplos de ello son Canadá e India (como ya expliqué). Esto también ha operado, aunque en menor medida, en EE.UU. ${ }^{163}$.

Este tipo de instrumentos parece más posible en Estados que pertenecen a la tradición del derecho continental europeo, debido a la ausencia de una doctrina del precedente y a los efectos generalmente relativos de las sentencias de sus tribunales. Incluso una declaración judicial de inconstitucionalidad con efectos generales tendrá efectos más limitados que los fallos constitucionales anglosajones, ya que ellas solo invalidan un precepto legal específico que ha sido impugnado, dejando a salvo la posibilidad de que el legislador produzca otra norma equivalente (la que solo podría ser controlada por un tribunal constitucional). En el modelo norteamericano, en cambio, el precedente haría posible que cualquier juez declare la inconstitucionalidad de la nueva ley, disminuyendo el ámbito de acción del legislador. En cambio, en los países del derecho civil que cuentan con tribunales constitucionales, habría que esperar que la causa llegue nuevamente a la competencia de la justicia constitucional, cuestión que no necesariamente sucede; y en caso de llegar a ser conocida por el tribunal constitucional, habría que esperar que los cambios en su composición (que son frecuentes en este modelo) no hayan alterado la doctrina que utilizó el mismo en el primer caso.

Examinemos brevemente la experiencia chilena. Existen dos herramientas que los poderes electos democráticamente pueden usar para revertir una sentencia del Tribunal Constitucional: (a) la ley de reforma constitucional y (b) otro tipo de ley, sea interpretativa de la constitución u otra categoría diversa.

Mediante el primer mecanismo (a), debe tomarse en cuenta que el procedimiento de modificación constitucional es más rígido que el de la ley simple, aunque cuenta con mayores grados de flexibilidad que la reforma constitucional en EE.UU. ${ }^{164}$. Piénsese que la constitución de los EE.UU. es de 1787 y se le han introducido 27 enmiendas, mientras la

163 La legislación que revierte decisiones judiciales es una realidad en los EE.UU. Sin embargo, las decisiones constitucionales son raras, ya que es muy difícil modificar la constitución. Véase la evidencia proporcionada por BARnes (2004).

164 Ver el procedimiento de reforma de la Constitución norteamericana en su art. V. 
Constitución chilena es de 1980 y se ha modificado en varias oportunidades mediante 30 leyes de reforma constitucional ${ }^{165}$. A lo menos dos de esas reformas son estructurales ${ }^{166}$.

En el breve período de vigencia de la Constitución de 1980, algunas modificaciones han perseguido corregir la Carta Fundamental debido a sentencias judiciales. Un ejemplo es el caso de la "Última Tentación de Cristo", ocurrido el año 2001, cuando se eliminó la censura cinematográfica y se sustituyó por un sistema de calificación, además de reconocer el derecho a la libre creación artística (ley de reforma constitucional $N^{\circ} 19.742$ ). Esta modificación puso término a una jurisprudencia de la Corte Suprema, luego de lo dispuesto por una sentencia de la Corte Interamericana de Derechos Humanos ${ }^{167}$.

Otro ejemplo ocurrió con la aprobación del tratado internacional que regula la Corte Penal Internacional. El Tribunal Constitucional declaró la inconstitucionalidad de este tratado el año 2002, impidiendo la promulgación del mismo sea promulgado ${ }^{168}$. No obstante, el año 2009 los promotores de este tratado obtuvieron el apoyo de las mayorías parlamentarias requeridas para modificar la Constitución. Gracias a ello, se adicionó una disposición transitoria a la Carta Fundamental, permitiendo explícitamente la aprobación del tratado. Con ello, finalmente, el tratado de la Corte Penal Internacional pudo ser válidamente promulgado ${ }^{169}$

En ambos casos, las facciones políticas interesadas lograron generar una amplia mayoría parlamentaria que permitió la reforma constitucional. Bajo el modelo norteamericano, posiblemente estas modificaciones constitucionales no se habrían producido sin una alteración significativa de la jurisprudencia de la Corte Suprema. El sistema chileno, sin embargo, es mucho menos rígido que el sistema de enmiendas formales norteamericano, lo que favorece la aceptación de la idea del diálogo institucional. No hay que olvidar, en todo caso, que un sector de la doctrina nacional defiende la idea de los límites materiales a la reforma constitucional, ya que (según se argumenta) la potestad constituyente derivada estaría restringida por ciertos contenidos elementales de la constitución, como ocurre con los derechos esenciales ${ }^{170}$. Esta tesis presenta un problema obvio: restringe el diálogo institucional y hace que la supremacía en la interpretación judicial de la constitución se consolide de manera definitiva. De aceptarse esta tesis, entonces, la objeción democrática a la justicia constitucional se fortalece. Afortunadamente esta idea no ha sido recogida por la jurisprudencia.

\footnotetext{
165 Ver http://www.bcn.cl/lc/cpolitica/leyes-reforma-constitucion.

166 Me refiero a las reformas de 1989 (ley 18.825) y de 2005 (ley 20.050).

167 La sentencia de la Corte Suprema (17 de junio de 1997), confirmó sentencia de Corte de Apelaciones (20 de enero de 1997). La sentencia de la Corte Interamericana es de 5 de enero de 2001. Ver http://www.corteidh. or.cr/docs/casos/articulos/Seriec_73_esp.pdf

168 Sentencia del Tribunal Constitucional Rol No 346, 8 de abril de 2002.

169 Ver Ley de Reforma Constitucional No 20.352, publicada en el Diario Oficial el 30 de mayo de 2009. Cabe agregar que, luego de este proceso político, el tratado fue enviado nuevamente al control preventivo obligatorio del Tribunal Constitucional, el que lo declaró ajustado a la constitución. Sentencia del Tribunal Constitucional Rol No 1415, 24 de junio de 2009.

170 Ver Nogueira (2006) y Nogueira (2009). En un sentido contrario (aunque bajo el imperio de la Constitución de 1925) ver el antiguo fallo del Tribunal Constitucional Rol No 1415, 24 de junio de 2009.
} 
El segundo mecanismo (b) en que un fallo puede revertirse, es a través de una nueva ley. Este mecanismo puede ser de dos formas distintas: en primer lugar, puede ser mediante una ley interpretativa de la Constitución; o, en segundo lugar, a través de una ley diversa a la interpretativa. Este mecanismo se enfrenta a una objeción jurídica desde la perspectiva de las fuentes formales del Derecho, ya que sería contrario a la jerarquía de la Constitución el permitir que ella sea reformada mediante una ley. Pese a ello, si se acepta la idea de separar la idea de supremacía constitucional de la noción de supremacía judicial, la objeción precedente podría ser fácilmente contestada. Así, podría argumentarse que los fallos del Tribunal Constitucional que eliminan (con efectos expansivos) algún precepto legal, solo producen efectos respecto de dicho precepto, sin impedir la proliferación de nuevas leyes. Esto producirá una suerte de diálogo entre el Derecho (los jueces) y la política (el legislador) que puede ser saludable para el sistema democrático deliberativo. Como los parlamentarios, el Jefe de Estado y los ministros del Tribunal Constitucional cambian cada cierto tiempo (4, 8 ó 9 años, según corresponda), es posible esperar cambios en las posiciones que todas las instituciones relacionadas presentan.

Como la tradición jurídica del derecho civil no reconoce un precedente jurisprudencial vinculante, el diálogo institucional se hace más fácil. No existe una idea fuerte de supremacía judicial que tenga la capacidad de invalidar en la práctica el proceso político existente.

Un buen ejemplo de ese diálogo, tuvo su origen con un fallo de 2008, con el que el Tribunal Constitucional declaró la inconstitucionalidad de una regulación administrativa que autorizaba la distribución de la "píldora del día después"171. Se trató de una sentencia muy impopular ${ }^{172}$. Políticamente, era incorrecto que algún dirigente apoyara dicho fallo, razón por la que un grupo de parlamentarios propuso un proyecto de ley que autorizaba nuevamente la distribución de la misma. Ya no sería una regulación administrativa, sino que una ley. Algunos parlamentarios conservadores se abstuvieron de votar, otros modificaron sus posiciones, y solo unos pocos votaron en contra. El proyecto de ley que favorecía la píldora fue aprobado en el congreso ${ }^{173}$, con lo que la interpretación del Tribunal Constitucional quedó sin apoyo político, siendo contradicha por la lectura constitucional del legislador. Hoy, la píldora es lícita a pesar de la doctrina del Tribunal. Como el caso no ha vuelto a presentarse ante el Tribunal, no puede decirse que el diálogo entre instituciones haya finalizado aún ${ }^{174}$.

171 Sentencia del Tribunal Constitucional Rol No 740, 28 de abril de 2008.

172 Una encuesta de 2008 reveló que el 73.1\% de la población entre 13 y 39 años creía que la píldora no producía efectos abortivos. http://www.emol.com/noticias/nacional/detalle/detallenoticias.asp?idnoticia=301759

173 Ver la ley No 20.418, de enero de 2010.

174 Ver también algunos ejemplos en que la legislatura no se ha sometido a la doctrina jurisprudencial del Tribunal Constitucional en Fermandois (2005). Debe advertirse, en todo caso, que este autor es partidario de que todos los órganos del Estado se sujeten a lo dispuesto por dicho tribunal y se muestra crítico de la "desobediencia" del legislador. Si de lo anterior se sigue que las sentencias del Tribunal Constitucional son finales, entonces, ineludiblemente, se reducirá la capacidad del sistema político para estimular el diálogo institucional que propongo. 
Como puede observarse a raíz de este caso, es posible que una mayoría parlamentaria se imponga en contra de una sentencia constitucional. Ello permite inferir que, al menos en este tipo de cuestiones constitucionales, los jueces no tienen la última palabra.

También, hay que considerar que la sentencia derogatoria de las leyes, uno de los mecanismos posibles de revisión judicial que se encuentra disponible en nuestro sistema (tal vez el más importante debido a sus efecto) es muy difícil que tenga lugar, debido a que dicho fallo requiere de la mayoría de los $4 / 5$ de los ministros (8 votos de 10). Esta regla de quórum especial obliga a los jueces a producir amplios acuerdos internos, lo que hace que la revisión judicial de las leyes (por esta vía) opere de forma excepcional ${ }^{175}$.

De acuerdo a los puntos que desarrollados en los párrafos precedentes, los poderes del Tribunal Constitucional se encuentran limitados por (a) un requerimiento de supermayoría; (b) una integración mixta y representativa de otros poderes estatales; (c) la posibilidad de que sus sentencias sean revertidas por el poder político; (d) un texto constitucional relativamente denso en materias fundamentales (aunque no en todas); (e) una reciente tesis de deferencia que aún está en etapa de elaboración; (f) cargos de juez de duración limitada, lo que facilita cambios jurisprudenciales; y (g) la imposibilidad de los ministros decidan su propia agenda, entre otros.

Lo anterior permite concluir que la objeción de Waldron contra la revisión judicial de las leyes tiene un espacio más reducido en nuestro sistema político y jurídico. La discusión nacional debería, entonces, considerar las importantes diferencias explicadas.

\section{CONCLUSIONES}

El debate acerca de la legitimidad democrática de la justicia constitucional es complejo, y debe ser adaptado a la realidad de los países en que este se plantea.

Para lo anterior, debe considerarse (a) la tradición jurídica en que el país se sitúa y (b) los arreglos institucionales del sistema político que, junto con relativizar la noción de supremacía judicial, limitan la discrecionalidad de los jueces en la interpretación de la Constitución.

El argumento de Waldron puede ser respondido desde diferentes perspectivas, y es necesario situarlas en un contexto adecuado para que dichas respuestas tengan alguna cabida. No es lo mismo argumentar sobre la base de las deficiencias del modelo de justicia constitucional que Waldron critica (el de Dworkin, enfocado a los EE.UU.), a hacerlo desde la perspectiva de sistemas institucionales diferentes.

Mi trabajo se ha centrado en analizar de qué manera las diferentes nociones en la teoría de la interpretación constitucional y en los diferentes sistemas políticos y tradiciones jurídicas, permiten separar la idea de la supremacía constitucional de la supremacía judicial. Para ello, es necesario revisar la capacidad de los órganos democráticamente electos de interpretar la Constitución, incluso en contra de las sentencias que jueces constitucionales

175 En efecto, esta atribución solo ha sido ejercida en los siguientes casos: sentencia del Tribunal Constitucional Rol No 681, 26 de marzo de 2007; Sentencia del Tribunal Constitucional Rol No 1254, 29 de julio de 2009; Sentencia del Tribunal Constitucional Rol No 1345, 25 de mayo de 2019; Sentencia del Tribunal Constitucional Rol No 1710, 6 de agosto de 2010. 
han elaborado. Mientras más puedan separarse estas dos ideas, que normalmente se presentan juntas, menos cabida tendrá la objeción democrática a la justicia constitucional.

Como consecuencia de lo anterior, propongo avanzar hacia un modelo de justicia constitucional que permita un diálogo libre entre instituciones, donde no se cierre el debate cuando una sentencia resuelve un caso particular o cuando el legislador regula una materia específica. Las instituciones relevantes (Tribunal Constitucional, Congreso, Presidente de la República) gozan de continuas y periódicas modificaciones en su composición, lo que permite dar mayor flexibilidad a una conversación saludable entre política y Derecho. El diseño institucional chileno, sumado a la tradición jurídica del derecho civil, es favorable a la idea del diálogo institucional. La experiencia nacional ha dado muestras de que ese diálogo es posible, pero no debe olvidarse que la existencia del mismo nos obliga a revisar la manera en que entendemos algunas instituciones jurídicas como la cosa juzgada constitucional, cuestión que me propongo examinar en investigaciones futuras.

\section{BIBLIOGRAFÍA}

Ackerman Bruce (1993): We The People. Foundations (New York, The Belknap Press of Harvard University Press) 369 pp.

Ackerman Bruce (1998): We The People. Transformations (New York, The Belknap Press of Harvard University Press) 538 pp.

Ackerman, Bruce (2007): “The Living Constitution”, Harvard Law Review, vol. 120: pp. 1737-1812.

Aldunate Lizana, Eduardo (2001): "La desconstitucionalización de la constitución” Revista de Derecho de la Universidad Católica de Valparaíso, vol. XXII: pp. 17-36.

Atria, Fernando (1993): “Tribunal Constitucional y Objeción Democrática”, Revista Chilena de Derecho, vol. 20 No 2-3: pp. 367-378.

Atria, Fernando (2000a): "Revisión Judicial: el Síndrome de la Víctima Insatisfecha”. Disponible en: http://www.cepchile.cl/dms/lang_1/doc_1081.html [Fecha de consulta: 17 de agosto 2011].

Atria, Fernando (2000): "Verdad, Política, Derecho". Disponible en: http://redalyc.uaemex.mx/redalyc/src/inicio/ArtPdfRed.jsp?iCve=19760138 [Fecha de consulta: 17 de agosto 2011].

Barnes, Jeb (2004): Legislative Overrides, Pluralism, and Contemporary Court-Congress Relations (California, Stanford University Press) $219 \mathrm{pp}$.

Bickel, Alexander (1962 edición de 1986): The Least Dangerous Branch (New York, Yale University Press) 303 pp.

Bork, Robert H. (1990): The Tempting of America. The Political Seduction of the Law (New York, Touchstone) $430 \mathrm{pp}$.

Bon, Pierre (1993): "El Conseil Constitutionnel francés y el modelo de Cortes Constitucionales europeas", Revista Chilena de Derecho, vol. 20 No 2-3: pp. 379-394.

Cappelletti, Mauro (1986): "Repudiating Montesquieu? "The Expansion and Legitimacy of 'Constitutional Justice'”, Catholic University Law Review, vol. 35: pp. 1-32. 
Carroll, Royce y Tiede, Lydia (2010): "Conflict on Chile's Constitutional Tribunal”, (5th Annual Conference on Empirical Legal Studies Paper). Disponible en: http://papers.ssrn. com/sol3/papers.cfm?abstract_id=1630986\& [Fecha de consulta: 3 de agosto 2011].

Carter, Lief y Burke, Thomas (2004): Reason in Law (California, Longman) 194 pp.

Charters, Claire (2006): "Responding to Waldron's Defense of Legislatures: Why New Zealand's Parliament Does Not Protect Rights in Hard Cases", New Zealand Law Review: pp. 621-663.

Correa, Raúl (2009): "Vulgarización por constitucionalización”, en: Facultad de Derecho Universidad de Chile (edit.), Democracia y Derechos Fundamentales desde la Filosofía Política (Santiago, Editorial Jurídica de Chile) pp. 35-54.

Cross, Frank B. y Tiller, Emerson H. (1998): "Judicial Partisanship and Obedience to Legal Doctrine: Whistleblowing on the Federal Courts of Appeals", Yale Law Journal, vol. 107: pp. 2155-2176.

Cohen, Joshua (1989): "Deliberation and Democratic Legitimacy", en: Hamlin y Pettit (edit.), The Good Polity: Normative Analysis of the State (Oxford, Basil Blackwell) pp. 17-34.

Cooke, Jacob E. (1961): The Federalist (Connecticut, Wesleyan University Press) 672 pp.

Cooter, Robert (2000): The Strategic Constitution (New Jersey, Princeton University Press) 440 pp.

Dahl, Robert (1991): Democracy and Its Critics (New York, Yale University Press) 397 pp.

Dahl, Robert (2003): How Democratic is the American Constitution? (New York, Yale University Press) $224 \mathrm{pp}$.

De Lora, Pablo (2002): "La Presunción de Constitucionalidad de las Leyes: Una Visita a la Regla Thayer", en: Carbonell, M. (compilador), Teoría Constitucional y Derechos Fundamentales (México, Comisión Nacional de los Derechos Humanos) pp. 409-441.

Deva, Surya (2010): "Constitutional Courts as 'Positive Legislators': The Indian Experience”. Disponible en: http://papers.ssrn.com/sol3/papers.cfm?abstract_id=1620224 [Fecha de consulta: 3 de agosto 2011].

Dixon, Rosalind (2009): “The Supreme Court of Canada, Charter Dialogue, and Deference", Osgoode Hall Law Journal, vol. 47: pp. 235-286.

Dworkin, Ronald (1986): Law's Empire (New York, Belknap Press) 470 pp.

Dworkin, Ronald (1996): Freedom's Law (New York, Harvard University Press) 427 pp.

Eisgruber, Christopher (2003): "Democracy and Disagreement: A Comment on Jeremy Waldron's Law and Disagreement", New York University Journal of Legislation and Public Policy, vol.6, 2003: pp. 35-48.

Elster, Jon (1984): Ulysses and the Sirens: Studies in Rationality and Irrationality (New York, Cambridge University Press) 193 pp.

Ely, John H. (1980): Democracy and Distrust, Harvard (New York, University Press) 268 pp.

Estlund, David (2000): "Jeremy Waldron on Law and Disagreement", Philosophical Studies, vol. 99: pp. 111-128.

Fallon, Richard H. Jr. (2008): “Core of an Uneasy Case for Judicial Review”, Harvard Law Review, vol. 121: pp. 1693-1736.

Favoreu Louis J. (1994): Los Tribunales Constitucionales (Barcelona Editorial Ariel S.A.) 158 pp. 
Favoreu, Louis J. (2001): "La Constitucionalización del Derecho", Revista de Derecho, Universidad Austral de Chile, vol. 12 No 1: pp. 31-43.

Fermandois, Arturo (2005): "Efecto Vinculante de las Sentencias del Tribunal Constitucional”, Zúñiga (coordinador), Reforma Constitucional (Santiago, LexisNexis) pp. 685-696.

Figueroa García-Huidobro, Rodolfo (2007): "Concepto de Persona, Titularidad del Derecho a la Vida y Aborto”, Revista de Derecho, Universidad Austral de Chile, vol. XX: pp. 95-130.

Figueroa García-Huidobro, Rodolfo (2009): "Justiciabilidad de los Derechos Económicos, Sociales y Culturales. Discusión teórica”, Revista Chilena de Derecho, vol. 36 No 3: pp. 587-620.

Fix-Zamudio, Héctor (1999): "Justicia Constitucional y Judicialización de la Política", en: Orozco Henríquez, J. J. (coordinador), Sistemas de Justicia Electoral: Evaluación y Perspectivas (México, UNAM) pp. 11-38.

Fletcher, William A. (2009): "Dissent”, Golden Gate University Law Review, vol. 39: pp. 291-300.

Freeman, Stewart (1990): "Constitutional Democracy and the Legitimacy of Judicial Review”, Law and Philosophy, vol. 9: pp. 327-370.

Friedman, Barry (2006): “Taking Law Seriously", Perspectives on Politics, vol. 4, No 2: pp. 261-276.

García, José F. (2008): "El Proceso Legislativo Sin Romance: implicancias para el Diseño Constitucional Chileno", Ius et Praxis, vol. $14 \mathrm{~N}^{\circ}$ 2: pp. 489-522.

García de Enterría, Ernesto (2006): La Constitución como Norma y el Tribunal Constitucional (Navarra, Thomson Civitas).

Goutal, Jean L. (1976): "Characteristics of Judicial Style in France, Britain and the U.S.A”., The American Journal of Comparative Law, vol. 24: pp. 43-72.

Habermas, Jürgen (1996): Between Facts and Norms (Massachusetts, MIT Press) 631 pp.

Hart, H.L.A (1994): The Concept of Law (New York, Oxford University Press) 262 pp.

Hogg, Peter (1984): "Canada's New Charter of Rights" The American Journal of Comparative Law, vol. 32, No 2: pp. 283-305.

Hutchinson, A. y Colón-Ríos, J. (2011): “Constituciones Duraderas. Una Crítica Democrática”, en: Couso, Javier (coordinador), Anuario Derecho Público Universidad Diego Portales (Santiago, Ediciones UDP) pp. 437-460.

Jayasurya, Gautam (2010): “Indian Judiciary: From Activism to Restraint". Disponible en: http://ssrn.com/abstract=1601843 [Fecha de consulta: 3 de agosto 2011].

Kelsen, Hans (2008): "La Garantía Jurisdiccional de la Constitución (La Justicia Constitucional)", Revista Iberoamericana de Derecho Procesal Constitucional, vol. 10: pp. 3-46.

Kelsen, Hans (1942): "Judicial Review of Legislation: A Comparative Study of the Austrian and the American Constitution", The Journal of Politics, vol. 4 No 2: pp. 183-200.

Kramer, Larry (2004): The People themselves: Popular Constitutionalism and Judicial Review, New York, Oxford University Press) 363 pp.

Laporta, Francisco J. (2001): "El Ámbito de la Constitución”, Doxa: Cuadernos de filosofía del derecho, Vol. 24: pp. 459-484. 
Lasser, Michael (2004): Judicial Deliberations. A Comparative Analysis of Judicial Transparency and Legitimacy (New York, Oxford University Press) 396 pp.

Lasser, Michael (2009): “Transforming Deliberations," en Huls, N, Adams, M, y Bomнoff, J. (edit.), The Legitimacy of Highest Courts' Rulings. Judicial Deliberation and Beyond (New York, Cambridge University Press) pp. 33-53.

Lawson, Gary (1994): “The Constitutional Case against Precedent”, Harvard Journal of Law \& Public Policy, vol. 17: pp. 23.

Lawson, Gary (1996): "Legal Indeterminacy: its Cause and Cure" Harvard Journal of Law \& Public Policy, vol. 19: pp. 411-448.

Lawson, Gary (2007): "Mostly Unconstitutional: the Case against Precedent Revisited", Ave Maria Law Review, vol. 5: pp. 1-22.

Linares, Sebastián (2008): "Sobre el Ejercicio Democrático del Control Judicial de las Leyes”, Isonomía, vol. 28: pp. 149-184.

Lindquist, Stephen A. y Cross, Frank B. (2005): "Empirically Testing Dworkin's Chain Novel Theory: studying the Path of Precedent", New York University Law Review, vol. 80: pp. 1156-1206.

Martínez Estay, José I. (2010): "Los Derechos Sociales de Prestación en la Jurisprudencia Chilena”, Estudios Constitucionales, vol. 8, No 2: pp. 125-166.

Mcbain, Howard L. (1927): The Living Constitution (London, The MacMillan Company) 284 pp.

Merryman, John H. y Pérez-Perdomo, Rogelio (2007): The Civil Law Tradition (California, Stanford University Press) 173 pp.

Michelman, Frank (1999): Brennan and Democracy (New Jersey, Princeton University Press) $160 \mathrm{pp}$.

Morton, Frank L. (1988): "Judicial Review in France: A Comparative Analysis", American Journal of Comparative Law, vol. 36, No 1: pp. 89-110.

Nogueira, Humberto (2006): "Los Límites del Poder Constituyente y el Control de Constitucionalidad de las Reformas Constitucionales en Chile”, Estudios Constitucionales, vol. $4 \mathrm{~N}^{\circ}$ 2: pp. 435-455.

Nogueira, Humberto (2009): “Consideración sobre Poder Constituyente y Reforma de la Constitución en la Teoría y la Práctica Constitucional”, Ius Et Praxis, vol. 15 N 1: pp. 229-262.

Panaccio, Charles-Maxime (2010): "Professor Waldron goes to Canada (One More Time): The Canadian Charter and the Counter-Majoritarian Difficulty", Common Law World Review, vol.39: pp. 100-118.

Posner, Richard A. (1993): "What do Judges and Justices Maximize? (The Same Thing Everybody Else)", Supreme Court Economic Review, vol. 3: pp. 1-41.

Posner, Richard A. (2000): "Review of Jeremy Waldron, 'Law and Disagreement'”, Columbia Law Review, vol. 100, No 2:pp. 582-592.

Posner, Richard A. (2005): Law, pragmatism, and democracy (New York, Harvard University Press) 398 pp.

Posner, Richard A. (2008): How Judges Think (New York, Harvard University Press) 387 pp. 
Posner, Richard A. (2010): "The Rise and Fall of Judicial Self-Restraint”, inédito documento de trabajo presentado en el simposio Brennan Center Forde Symposium Lecture, Facultad de Derecho de la Universidad de California, Berkeley, 5 de octubre de 2010.

Radin, Max (1925): “The Theory of Judicial Decision: Or How Judges Think”. American Bar Association Journal, vol. 11: pp. 357-362.

Rivera León, Mauro A. (2010): "The Counter-Majoritarian Difficulty: Bickel and the Mexican Case", Mexican Law Review, vol. III No 1: pp. 25-48.

Rousseau, Dominique (2002): La Justicia Constitucional en Europa (Madrid, Centro de Estudios Políticos y Constitucionales) $140 \mathrm{pp}$.

Ruiz Miguel, Alfonso (2004): "Constitucionalismo y Democracia”, Isonomía, vol. 21: pp. 51-84.

Scalia, Antonin (1998): A Matter of Interpretation (New Jersey, Princeton University Press) $176 \mathrm{pp}$.

Segal, Jeffrey A. y Spaeth, Harold J. (1993): The Supreme Court and the Attitudinal Model (New York, Cambridge University Press) 390 pp.

Segal, Jeffrey A. y Spaeth, Harold J. (1996): "The Influence of Stare Decisis on the Votes of United State Supreme Court Justices", American Journal of Political Science, vol. 40: pp. 971-1003.

Shapiro, Martin (1994): "Judges as Liars", Harvard Journal of Law and Public Policy, vol. 17: pp. 155-156.

Schauer, Frederick (2000): "Incentives, Reputation, and the Inglorious Determinants of Judicial Behavior”, University of Cincinati Law Review, vol. 68: pp. 615-636.

Strauss, David A. (2010): The Living Constitution (New York, Oxford University Press) $150 \mathrm{pp}$.

Sunstein, Cass (2005): Why Societies Need Dissent (New York, Harvard University Press) $246 \mathrm{pp}$.

Tallon, Denis (1976): "The Constitution and the Courts in France", American Journal of Comparative Law, vol. 27, No 4: pp. 567-576.

Thayer, James B. (1893): "Origin and Scope of the American Doctrine of Constitutional Law”, Harvard Law Review, vol. VII: pp. 129-156.

Tushnet, Mark (1999): Taking the Constitution away from the Courts (New Jersey, Princeton University Press) $254 \mathrm{pp}$.

Tushnet, Mark (2006): “The Supreme Court and the National Political Order: Collaboration and Confrontation", en Kahn, Ronald y Kersh, Ken (editores), The Supreme Court and American Political Development (Kansas, Kansas University Press) pp. 117-138.

Unger, Roberto (1986): The Critical Legal Analysis movement (New York, Harvard University Press) 128 pp.

Verdugo R., Sergio (2008): "Desafuero Parlamentario por Delito de Acción Penal Privada: un caso de Inconstitucionalidad por Omisión del Legislador", en Universidad de Concepción, Derecho Público en el Siglo XXI. Reforma y Modernización del Estado, XXXVIII Jornadas Chilenas de Derecho Público, vol. 1: pp. 429-452.

Verdugo R., Sergio (2009): "Inconstitucionalidad por Omisión del Legislador", Actualidad Jurídica, Universidad del Desarrollo, vol. 19: pp. 373-396. 
Verdugo R., Sergio (2009-A): "Regla de Mayoría y Democracia: el caso de las Leyes Orgánicas Constitucionales”, Actualidad Jurídica, Universidad del Desarrollo, vol. 20: pp. 597-633.

Verdugo R., Sergio (2010): “Control Preventivo y Obligatorio: auge y Caída de la Toma de Razón al Legislador”, Estudios Constitucionales, año 8 No 1: pp. 201-248.

Verdugo R., Sergio (2010-A): "Entre la responsabilidad internacional del Estado y la supremacía de la Constitución: Una propuesta para enriquecer el debate nacional”, Actualidad Jurídica, Universidad del Desarrollo, vol. 22: pp. 55-100.

Waldron, Jeremy (1993): "A Right-Based Critique of Constitutional Rights", Oxford Journal of Legal Studies, vol.18: pp. 18-51.

Waldron, Jeremy (1994): "Freeman's Defense of Judicial Review", Law and Philosophy, vol.13: pp. 27-41.

Waldron, Jeremy (1998): "Moral Truth and Judicial Review", American Journal of Jurisprudence, vol.43: pp. 75-98.

Waldron, Jeremy (1999): The Dignity of Legislation (New York, Cambridge University Press) 206 pp.

Waldron, Jeremy (1999-A): Law and Disagreement (New York, Oxford University Press) $344 \mathrm{pp}$.

Waldron, Jeremy (2006): “The Core of the Case against Judicial Review", The Yale Law Journal, vol. 115, No. 6: pp. 1346-1406.

Waldron, Jeremy (2006-A): “Are Constitutional Norms Legal Norms?”, Fordham Law Review, vol. 75: pp. 1697-1714.

Zapata Larraín, Patricio (1994): La Jurisprudencia del Tribunal Constitucional (Santiago, Corporación Tiempo 2000) 250 pp.

Zapata Larraín, Patricio (2002): La Jurisprudencia del Tribunal Constitucional (Santiago, Biblioteca Americana Universidad Andrés Bello) 200 pp.

Zapata Larraín, Patricio (2008): Justicia Constitucional (Santiago, Editorial Jurídica de Chile), 623 pp.

Veto del Presidente Andrew Jackson (1832): Disponible en http://avalon.law.yale. edu/19th_century/ajveto01.asp [Fecha de consulta: 16 de agosto 2011]

\section{JURISPRUDENCIA CITADA}

\section{JURISPRUDENCIA NACIONAL}

Tribunal Constitucional Rol No 136, 26 de noviembre de 2001.

Tribunal Constitucional Rol No 309, 4 de agosto de 2000.

Tribunal Constitucional Rol No 346, 8 de abril de 2002.

Tribunal Constitucional Rol No 503, 19 de julio de 2006.

Tribunal Constitucional Rol No 552, 11 de marzo de 2008.

Tribunal Constitucional Rol No 626, 16 de enero de 2007.

Tribunal Constitucional Rol No 681, 26 de marzo de 2007.

Tribunal Constitucional Rol No 706, 30 de marzo de 2007. 
Tribunal Constitucional Rol No 740, 18 de abril de 2008.

Tribunal Constitucional Rol No 790, 11 de diciembre de 2007.

Tribunal Constitucional Rol No 1129, 29 de mayo de 2008

Tribunal Constitucional Rol No 1153, 30 de septiembre de 2008.

Tribunal Constitucional Rol No 1254, 29 de julio de 2009.

Tribunal Constitucional Rol No 1345, 25 de mayo de 2009.

Tribunal Constitucional Rol No 1357, 9 de julio de 2009.

Tribunal Constitucional Rol No 1415, 24 de junio de 2009.

Tribunal Constitucional Rol No 1463, 23 de septiembre de 2010.

Tribunal Constitucional Rol No 1678, 23 de julio de 2010.

Tribunal Constitucional Rol No 1710, 6 de agosto de 2010.

Tribunal Constitucional Rol No 1867, 30 de diciembre de 2010.

Tribunal Constitucional Rol No 1894, 12 de julio de 2011.

Tribunal Constitucional Rol No 2025, 20 de julio de 2011.

EXTRANJERA E INTERNACIONAL

Corte Suprema de Estados Unidos McCulloch v. Maryland 17 US 316 (1819).

Corte Suprema de Estados Unidos Dred Scott v. Sandford, 60 U.S. 393 (1857).

Corte Suprema de Estados Unidos Plessy v. Ferguson, 163 U.S. 537 (1896).

Corte Suprema de Estados Unidos Brown v. Board of Education, 347 U.S. 483 (1954).

Corte Suprema de Estados Unidos Baker v. Carr, 369 U.S. 186 (1962).

Corte Suprema de Estados Unidos Roe v. Wade, 410 U.S. 113 (1973).

Corte Suprema de Estados Unidos Chevron 467 U.S. 837(1984).

Corte Suprema de Estados Unidos Planned Parenthood v. Casey 505 U.S. 833 (1992).

Corte Suprema de Estado Unidos Nixon v. United States, 506 U.S. 224 (1993).

Corte Suprema de Estados Unidos Bush v. Gore, 531 U.S. 98 (2000).

Corte Suprema de Estados Unidos Vieth v. Jubelirer, 541 U.S. 267 (2004).

Corte Suprema de India His Holiness Kesavananda Bharati v. The State of Kerala and Others (AIR 1973 SC 1461).

Corte Europea de Derechos Humanos Boso v. Italia (2002), 5 de septiembre de 2002.

Corte Europea de Derechos Humanos Vo v. Francia (2004), 8 de julio de 2004.

Corte Europea de Derechos Humanos Evans v. Reino Unido (2007), 10 de abril de 2007.

Corte Europea de Derechos Humanos Tysiac v. Polonia (2007), 24 de septiembre de 2007.

Corte Europea de Derechos Humanos Open Door and Dublin Well Woman v. Irlanda (1992), 29 de octubre de 1992.

\section{NORMAS CITADAS}

Ley de reforma Constitucional No 18.825, modificación general de la Constitución Política de la República. Diario Oficial, 17 de agosto de 1989. 
Ley de reforma constitucional No 20.050, introduce diversas modificaciones a la Constitución Política de la República. Diario Oficial, 26 de agosto de 2005.

Ley de reforma constitucional $\mathrm{N}^{\circ}$ 20.352, reforma constitucional que autoriza al Estado para reconocer el Estatuto de Roma, que crea la Corte Internacional Penal. Diario Oficial, 30 de mayo de 2009. 